Hydrol. Earth Syst. Sci., 18, 1053-1072, 2014

www.hydrol-earth-syst-sci.net/18/1053/2014/

doi: 10.5194/hess-18-1053-2014

(C) Author(s) 2014. CC Attribution 3.0 License.

\title{
A comparison of methods for determining field evapotranspiration: photosynthesis system, sap flow, and eddy covariance
}

\author{
Z. Zhang ${ }^{1}$, F. Tian ${ }^{1, *}$, H. Hu${ }^{1}$, and P. Yang ${ }^{1}$ \\ ${ }^{1}$ State Key Laboratory of Hydroscience and Engineering, Department of Hydraulic Engineering, Tsinghua University, \\ Beijing, 100084, China \\ " now at: State Key Laboratory of Hydroscience and Engineering, Department of Hydraulic Engineering, Tsinghua University, \\ Beijing, China
}

Correspondence to: F. Tian (tianfq@tsinghua.edu.cn)

Received: 13 October 2013 - Published in Hydrol. Earth Syst. Sci. Discuss.: 19 November 2013

Revised: 31 January 2014 - Accepted: 4 February 2014 - Published: 18 March 2014

\begin{abstract}
A multi-scale, multi-technique study was conducted to measure evapotranspiration and its components in a cotton field under mulched drip irrigation conditions in northwestern China. Three measurement techniques at different scales were used: a photosynthesis system (leaf scale), sap flow (plant scale), and eddy covariance (field scale). The experiment was conducted from July to September 2012. To upscale the evapotranspiration from the leaf to plant scale, an approach that incorporated the canopy structure and the relationships between sunlit and shaded leaves was proposed. To upscale the evapotranspiration from the plant to field scale, an approach based on the transpiration per unit leaf area was adopted and modified to incorporate the temporal variability in the relationship between leaf areas and stem diameter. At the plant scale, the estimate of the transpiration based on the photosynthesis system with upscaling was slightly higher (18\%) than that obtained by sap flow. At the field scale, the estimates of transpiration derived from sap flow with upscaling and eddy covariance showed reasonable consistency during the cotton's open-boll growth stage, during which soil evaporation can be neglected. The results indicate that the proposed upscaling approaches are reasonable and valid. Based on the measurements and upscaling approaches, evapotranspiration components were analyzed for a cotton field under mulched drip irrigation. During the two analyzed sub-periods in July and August, evapotranspiration rates were 3.94 and $4.53 \mathrm{~m} \mathrm{day}^{-1}$, respectively. The fraction of transpiration to evapotranspiration reached $87.1 \%$ before drip irrigation and $82.3 \%$ after irrigation. The high fraction
\end{abstract}

of transpiration over evapotranspiration was principally due to the mulched film above the drip pipe, low soil water content in the inter-film zone, well-closed canopy, and high water requirement of the crop.

\section{Introduction}

Evapotranspiration (ET) is a major component in energy balance and water cycling (Katul et al., 2012). Much effort has been devoted to the measurement of ET because it is a critically important process in many fields, including hydrology, ecology, agriculture, forestry, and horticulture. Over the past few decades, several different techniques, including the use of eddy covariance, lysimeter, Bowen ratio, soil water budget, large-aperture scintillometer, sap flow, and photosynthesis system (also known as leaf gas exchange instrument), have been developed (Evett et al., 2012; Lei and Yang, 2010; MacKay et al., 2002). In general, transpiration at the leaf scale can be reliably measured through a photosynthesis system using the high-quality humidity sensors in the leaf chamber. At the plant scale, sap flow based on stem energy balance theory is widely applied to measure transpiration, particularly in herbaceous plants. Lysimeter and soil water budget methods can directly estimate ET based on the mass balance principle, but representativeness of the control volume is still dubious, especially under conditions of inhomogeneous soil moisture distribution caused by drip irrigation. Although ET can be obtained by Bowen ratio and the large-aperture 
scintillometer, eddy covariance is generally considered the most reliable and state-of-the-art technique for the accurate measurement of ET at the field scale.

The abovementioned measurement techniques are essentially different in terms of instrumentation, applicable spatial scale, and theoretical background (Alfieri et al., 2012). Due to the different spatial scales to which ET measurement methods are applied, scale transformation approaches should be used to make ET values measured by different methods comparable (Evett et al., 2012). Additionally, through comparisons, scale transformation approaches can be validated and improved.

Using valid scale transformation approaches, ET values can be inferred outside of their observed scales and compared at the same scale (Evett et al., 2012). For instance, field evapotranspiration can be obtained after upscaling the measurements obtained using the photosynthesis system and sap flow. A comparison of ET measured at different scales can not only allow for the determination of the accuracy and uncertainty of these independent measurements but also provide solid and reliable ET estimates (Allen et al., 2011b). Additionally, different techniques are often combined with appropriate scale transformation approaches in water research, such as the partitioning of evaporation and transpiration in an ecosystem, and the development of ET models from groundbased data or remote sensing images (Alfieri et al., 2012; Williams et al., 2004). In addition, the extrapolations of water use from the level of individual leaf to the whole plant, as well as the extrapolations from individual plant to a stand of plants by using upscaling approaches, represent a critical step in the linking of plant physiology and hydrology (Hatton and $\mathrm{Wu}, 1995)$.

Several studies have compared sap flow, soil water budget, Bowen ratio, and eddy covariance measurements in a forest ecosystem (Granier et al., 2000; Silberstein et al., 2001; Williams et al., 2004; Wilson et al., 2001). These studies have primarily focused on the applicability of these techniques, evapotranspiration components, and the energy balance in the forest ecosystem. The approaches used in these studies to upscale from the plant (sap flow) to field scale (eddy covariance) were mainly based on plant population and the size of plant stems.

Cotton is one of the most important fiber economic crops (Ashraf, 2002). A number of ET measurements in cotton fields have been performed using one of these different techniques, such as eddy covariance (Zhou et al., 2011), lysimeter (Howell et al., 2004; Ko et al., 2009; Tolk et al., 2006) and sap flow (Dugas et al., 1994; Tang et al., 2010). Several comparisons of ET measurements in cotton field have also been carried out. Comparisons of ET measurements using the sap flow and lysimeter methods (Dugas, 1990) or the sap flow and Bowen ratio methods (Ham et al., 1990) have been implemented under flood irrigation conditions. The approaches used to upscale ET from the plant to field scale were based on plant population and stem size (similarly to studies conducted in the forest ecosystem) (Dugas, 1990) or on plant population and sampled plant leaf area (Ham et al., 1990). Both of these approaches demonstrated that the cotton transpiration measured by sap flow was higher than those measured by the lysimeter and the Bowen ratio. Additionally, these studies suggested that sap flow should be expressed per unit leaf area to improve field ET estimates. It was hypothesized that the upscaling approaches based on an accurate estimate of field leaf area would provide reliable results. Alfieri et al. (2012) and Chavez et al. (2009) compared ET values obtained by eddy covariance with that measured by lysimeter, and discussed the causes of discrepancy between them. However, comparison of ET measurements in agricultural crop fields under water-saving irrigation conditions is limited. In addition, a comparison of the photosynthesissystem-based method with other techniques has rarely been performed in previous studies. The partitioning of ET under mulched drip irrigation using these methods is seldom reported.

Mulched drip irrigation, which is a new micro-irrigation approach that incorporates the surface drip irrigation method and the film mulching technique, has been widely applied in northwestern China (Wang et al., 2011). Using this irrigation method, the fraction of transpiration over ET can be markedly increased by delivering water precisely to the root zone and by eliminating of the majority of useless soil evaporation via mulching (Zhang et al., 2014). Soil thermal conditions are also improved by mulching to ensure crop germination and seedling growth (Bonachela et al., 2001; Hou et al., 2010; Li et al., 2008). In 2009, mulched drip irrigation was adopted in fields with an area amounting to more than 1.2 million hectares in the Xinjiang Province of China. Mulched drip irrigation is also potentially applicable to other arid and semi-arid regions with similar climatic and farming conditions based on the abovementioned noteworthy advantages (Zhang et al., 2014). Because matter/energy exchanges on the land surface, including those of water and heat, are significantly altered by mulched drip irrigation (Zhou et al., 2011), a comprehensive study of ET using integrated measurements should be conducted in order to obtain a more thorough understanding of this process. In this study, three different ET measurement methods (i.e., photosynthesis system at the leaf scale, sap flow at the plant scale, and eddy covariance at the field scale) were compared in a crop field under mulched drip irrigation condition. The approaches for upscaling ET from the leaf scale to the plant scale and from the plant scale to the field scale were discussed and improved, and evapotranspiration and its components were determined for the analyzed periods. 


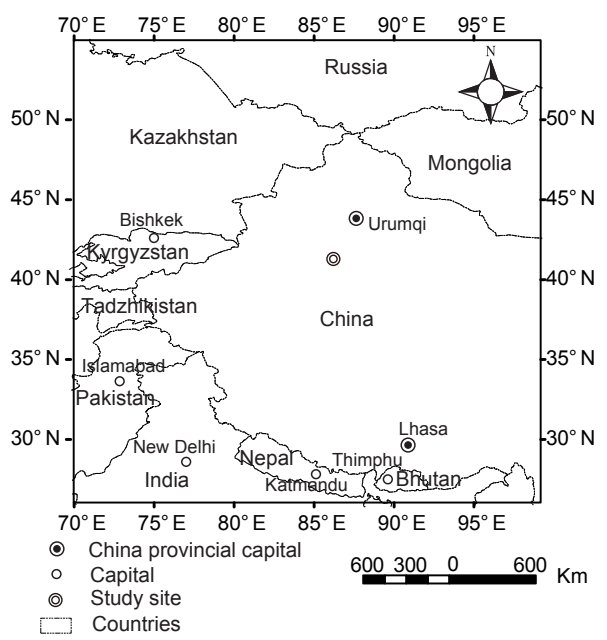

(a) Geographic location of the study site

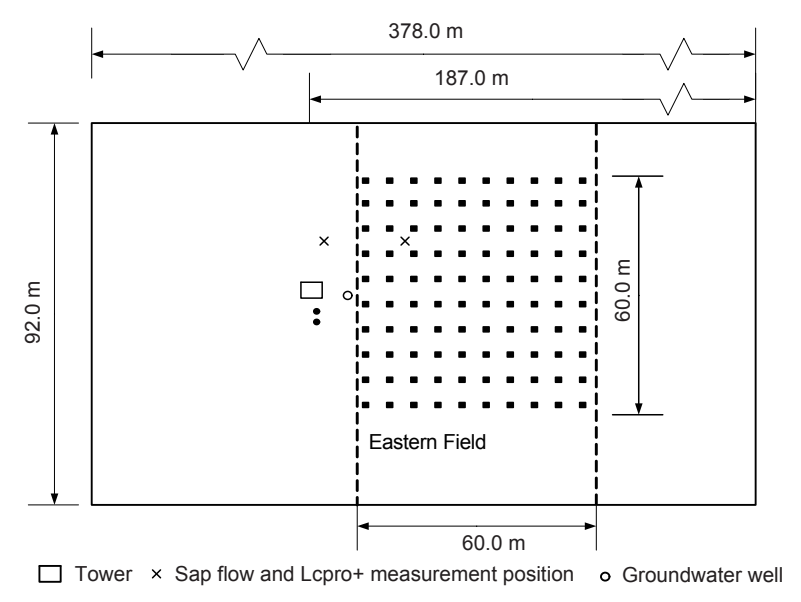

- Soil water moisture measurement profile $-6 \times 6 \mathrm{~m}^{2}$ plots for vegetation measurements

(b) Experimental field layout

Fig. 1. Geographic location of the study site and experimental field layout.

\section{Methods and materials}

\subsection{Experimental site and cotton planting}

The experimental site $\left(86^{\circ} 12^{\prime} \mathrm{E}, 41^{\circ} 36^{\prime} \mathrm{N} ; 886 \mathrm{~m}\right.$ a.s.l.; see Fig. 1) is located on the northeast edge of Taklimakan Desert, which belongs to the Bayangol Prefecture of Xinjiang Province in northwestern China. The study area is characterized by a typical inland arid climate with strong diurnal temperature fluctuation and scarce precipitation. The mean annual precipitation is approximately $60 \mathrm{~mm}$. The annual mean temperature is $11.48^{\circ} \mathrm{C}$, and the annual total sunshine duration is $3036 \mathrm{~h}$, which is favorable for cotton growth. The mean annual potential evaporation measured with a $\Phi 20$ evaporation pan is $2788 \mathrm{~mm}$ (Zhang et al., 2014). The major soil type in the experimental region is silt loam, and saturated volumetric water content is 0.42 . The planted

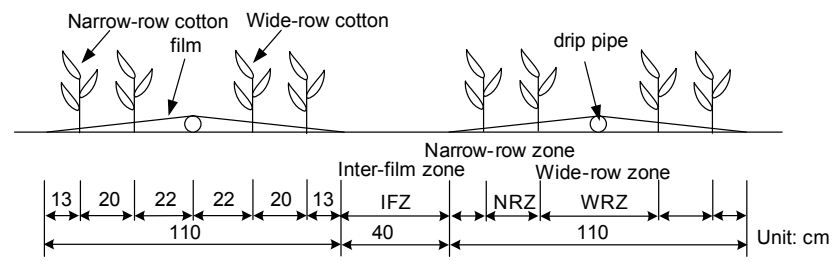

Fig. 2. One pipe, one film, and four rows of cotton arrangement.

crop is cotton (Gossypium hirsutum L.). It is the predominant economic crop in Xinjiang Province, which contributes nearly $50 \%$ of the total lint yield of China, with approximately 3.2 million tons produced in 2012 (http://english.gov. $\mathrm{cn} / 2012-10 / 14 /$ content2242953.htm).

The experimental cotton field had an area of 3.48 ha. A $10 \mathrm{~m}$ stationary tower was erected in the middle of the field to mount flux and meteorological instruments. Because the prevailing wind blows from the northeast, sap flow and photosynthesis system measurements were both conducted on the north side of the tower, where the potential source of the water flux was measured through eddy covariance. The surrounding field had the same cotton planting and irrigation conditions as the experimental field, which provided adequate fetch for the meteorological measurements. The profiles for soil water content measurements were located on the south side of the tower. The east part of the field, which was denoted the Eastern Field, was divided into 100 sub-plots with an area of $6 \times 6 \mathrm{~m}^{2}$ to measure the spatial distribution of cotton (Fig. 1).

The style of cotton planting and drip pipe arrangement is referred to as the "one pipe, one film, and four rows of cotton arrangement" (Hu et al., 2011), which indicates that one drip pipe beneath the mulched film is in the middle of four rows of cotton. The width of the film is $110 \mathrm{~cm}$, and the interfilm zone is $40 \mathrm{~cm}$. The three soil profile terms, i.e., wide-row zone, narrow-row zone, and inter-film zone, are defined as shown in Fig. 2.

In the experimental field, cotton was planted on 23 April 2012 and harvested from 20 September 2012 to 20 November 2012. The seeds were sown at $0.1 \mathrm{~m}$ intervals in each row to yield an anticipated population of 260000 plants ha $^{-1}$. However, the emergence rate in 2012 was $46.3 \%$ due to sandstorm and freezing damage, and actual plant density was 120000 plants ha $^{-1}$. Groundwater table depth varied from 2.09 to $3.27 \mathrm{~m}$ during the cotton growth period. The amount of irrigated water was $540.23 \mathrm{~mm}$ in total throughout the growth period, and the irrigation schedules adopted in 2012 are summarized in Table 1. To meet the plant requirements for nutrients, $173 \mathrm{~kg} \mathrm{ha}^{-1}$ compound fertilizers $\left(14 \% \mathrm{~N}, 16 \% \mathrm{P}_{2} \mathrm{O}_{5}\right.$, and $\left.15 \% \mathrm{~K}_{2} \mathrm{O}\right), 518 \mathrm{~kg} \mathrm{ha}^{-1}$ calcium superphosphate $\left(18 \% \mathrm{~N}\right.$ and $\left.40 \% \mathrm{P}_{2} \mathrm{O}_{5}\right)$, and $288 \mathrm{~kg} \mathrm{ha}^{-1}$ diammonium phosphate $\left(\mathrm{P}_{2} \mathrm{O}_{5}>16 \%\right)$ were applied as the basic fertilizer before plowing. As supplemental fertilizers during the growth period, approximately $293 \mathrm{~kg} \mathrm{ha}^{-1}$ urea 
Table 1. Irrigation schedule adopted for experiments in 2012.

\begin{tabular}{|c|c|c|c|c|c|c|c|c|c|c|c|c|c|}
\hline Cotton & \multicolumn{4}{|c|}{ Squaring stage } & \multicolumn{3}{|c|}{ Flower stage } & \multicolumn{5}{|c|}{ Bolls stage } & \multirow[t]{2}{*}{ Total } \\
\hline $\begin{array}{l}\text { Irrigation } \\
\text { date }\end{array}$ & $\begin{array}{l}6-10 / 11 \\
6-14 / 15\end{array}$ & $6-21$ & $6-28$ & $7-6 / 7$ & $7-15 / 16$ & $7-26$ & $8-4 / 5$ & $8-8$ & $8-12 / 13$ & $8-17$ & $8-22 / 23$ & $8-27 / 28$ & \\
\hline $\begin{array}{l}\text { Amount } \\
(\mathrm{mm})\end{array}$ & 65.17 & 34.35 & 35.32 & 36.77 & 33.26 & 44.10 & 40.00 & 59.28 & 46.73 & 42.19 & 50.84 & 52.22 & 540.23 \\
\hline
\end{tabular}

$(46 \% \mathrm{~N})$ and $586 \mathrm{~kg} \mathrm{ha}^{-1}$ drip compound fertilizer $(13 \% \mathrm{~N}$, $18 \% \mathrm{P}_{2} \mathrm{O}_{5}$, and $16 \% \mathrm{~K}_{2} \mathrm{O}$ ) were applied through the fertigation method, and $27 \mathrm{~kg} \mathrm{ha}^{-1}$ foliar fertilizer $\left(\mathrm{K}_{2} \mathrm{O}>34 \%\right.$ and $\mathrm{P}_{2} \mathrm{O}_{5}>52 \%$ ) was applied through the sprinkle method.

\subsection{Instruments}

\subsubsection{Photosynthesis system}

Leaf transpiration occurs simultaneously with photosynthesis, and photosynthesis system can be used as a reliable and accurate tool for the measurement of transpiration (Mahouachi et al., 2006; Mengistu et al., 2011). In this study, an LCpro+ photosynthesis system (model LCpro+, ADC BioScientific Ltd., Hertfordshire, England) was used to measure transpiration at the leaf scale.

The basic components of LCpro+ are a broad leaf chamber, an infrared gas analyzer, two high-quality humidity sensors, an air probe, and a console with a keyboard, display, and memory. The selected leaf was placed in the leaf chamber with a known area of the leaf $\left(6.25 \mathrm{~cm}^{2}\right)$ enclosed in the broad leaf chamber. The measurements were conducted in an open system configuration in which fresh gas was continually passed through the plant leaf chamber. The transpiration rates were calculated from the differences in the $\mathrm{H}_{2} \mathrm{O}$ concentration between the incoming gas (the reference levels) and the gas after passing the leaf specimen (the analysis levels). $\mathrm{H}_{2} \mathrm{O}$ concentration was measured using two high-quality humidity sensors contained inside the plant leaf chamber. The increasing concentration of water vapor can be converted to transpiration rate by the following equation (ADC BioScientific Ltd., 2004):

$M=\frac{\left(e_{\mathrm{an}}-e_{\mathrm{ref}}\right) \cdot u_{\mathrm{s}}}{P_{\mathrm{a}}}$,

where $M$ represents the transpiration rate of the measured leaf $\left(\mathrm{mmol} \mathrm{m}^{-2} \mathrm{~s}^{-1}\right), e_{\mathrm{an}}$ is the water vapor pressure leaving the leaf chamber after dilution correction (mbar), $e_{\text {ref }}$ is the water vapor pressure entering the leaf chamber (mbar), $u_{\mathrm{s}}$ is the mass flow of air entering the leaf chamber per square meter of leaf area $\left(\mathrm{mmol} \mathrm{m}^{-2} \mathrm{~s}^{-1}\right)$, and $P_{\mathrm{a}}$ is the atmospheric pressure (mbar). For a typical leaf, the $\mathrm{H}_{2} \mathrm{O}$ flux $M$ lies between 0 and $15 \mathrm{mmol} \mathrm{m}^{-2} \mathrm{~s}^{-1}$.

\subsubsection{Sap flow}

To measure the water use of individual plants and estimate the transpiration of the crop, sap flow gauges were used for stems that were $8-16 \mathrm{~mm}$ in diameter (model SGA9, SGA13, Dynamax, Inc., Houston, TX, USA); this measurement approach is based on the stem energy balance theory. This model of sap flow gauges was chosen because it is well adapted to small, non-ligneous stems and has been shown to be accurate in several important economic crops, including cotton (Baker and Vanbanel, 1987; Ham et al., 1990; Tang et al., 2010). The stem water flow rate is calculated using the following equation (Sakuratani, 1981, 1984):

$$
\begin{aligned}
F_{\mathrm{p}} & =3.6 \times 10^{6} \times\left[P_{\text {in }}-\frac{K_{\mathrm{ST}} \cdot A_{\text {stem }} \cdot\left(\mathrm{d} T_{\mathrm{u}}+\mathrm{d} T_{\mathrm{d}}\right)}{\mathrm{d} x}\right. \\
& \left.-K_{\mathrm{SH}} \cdot \mathrm{CH}\right] /\left(C_{\mathrm{w}} \cdot \mathrm{d} T\right),
\end{aligned}
$$

where $F_{\mathrm{p}}$ is the stem water flow rate $\left(\mathrm{g} \mathrm{h}^{-1}\right), P_{\text {in }}$ is a fixed amount of heat powered by a DC supply (W), $K_{\mathrm{ST}}$ is the thermal conductivity of the stem $\left(\mathrm{W} \mathrm{m}^{-1} \mathrm{~K}^{-1}\right), A_{\text {stem }}$ is the stem cross-sectional area $\left(\mathrm{m}^{2}\right), \frac{\mathrm{d} T_{\mathrm{u}}}{\mathrm{d} x}\left(\mathrm{~K} \mathrm{~m}^{-1}\right)$ and $\frac{\mathrm{d} T_{\mathrm{d}}}{\mathrm{d} x}\left(\mathrm{~K} \mathrm{~m}^{-1}\right)$ are the temperature gradients in the up and down directions, respectively, $\mathrm{d} x$ is the spacing between the thermocouple junctions (m), $K_{\mathrm{SH}}$ is the sheath conductivity $\left(\mathrm{W} \mathrm{mV}^{-1}\right), \mathrm{CH}$ is the radial-heat thermopile voltage $(\mathrm{mV}), C_{\mathrm{w}}$ is the specific heat of water $\left(\mathrm{J} \mathrm{kg}^{-1} \mathrm{~K}^{-1}\right), \mathrm{d} T$ is the temperature increase of the sap $(\mathrm{K})$, and $3.6 \times 10^{6}$ is a unit conversion factor. The second part of the equation, shown in square brackets, represents the axial heat conduction through the stem, and the third part represents the radial heat conducted through the gauge to the ambient air. Hence, the value enclosed in square brackets is heat convection carried by the sap. After dividing by the specific heat of water and the temperature increase of sap, the heat flux is directly converted to water flow rate. In particular, heat storage of the stem is assumed to be zero (Dugas, 1990).

\subsubsection{Eddy covariance}

The eddy covariance (EC) is known to be a reliable method for obtaining direct field ET measurements (Baldocchi et al., 2001). In this study, the EC system consists of a fast-response 3-D sonic anemometer (model CSAT3, Campbell Scientific 
Inc., Logan, UT, USA), a fast-response open-path infrared gas $\left(\mathrm{H}_{2} \mathrm{O}\right.$ and $\left.\mathrm{CO}_{2}\right)$ analyzer (model EC150, Campbell Scientific Inc., Logan, UT, USA), an air temperature/humidity sensor (model HMP155A, Vaisala Inc., Woburn, MA, USA), and a micrologger (model CR3000, Campbell Scientific Inc., Logan, UT, USA). The CSAT3 sensor was oriented toward the predominant wind direction with an azimuth angle of $50^{\circ}$ from true north. The net radiation at a height of $2.25 \mathrm{~m}$ (model LITE2, Kipp \& Zonen, Delft, the Netherlands) and soil heat flux (model HFP01SC, Hukseflux, the Netherlands; two plates were placed $0.05 \mathrm{~m}$ below the ground surface in the wide-row zone and inter-film zone, respectively) were measured to test the data quality based on energy balance closure.

Multiplying the vertical velocity fluctuations by a scalar (e.g., water vapor, carbon dioxide, and air temperature) concentration fluctuation can provide a direct estimate of the latent heat (LE), $\mathrm{CO}_{2}$, and sensible heat $(H)$ fluxes (see Eqs. 3 through 5) (van Dijk et al., 2004). The EC data were corrected in the post-processing calculations through the following methods: linear de-trend, tilt correction through the yaw and pitch rotation, density fluctuation correction, and correction of the sonic temperature for humidity (van Dijk et al., 2004; Webb et al., 1980). The missing data due to system failures or data rejection were filled using two strategies. Short gaps (less than $2 \mathrm{~h}$ ) were filled through a linear interpolation, and larger data gaps (more than $2 \mathrm{~h}$ and less than 1 day) were filled using the mean diurnal average method (Falge et al., 2001).

$$
\begin{aligned}
& \mathrm{FL}=\overline{\rho_{\mathrm{a}}} \overline{w^{\prime} s^{\prime}}, \\
& \lambda \mathrm{ET}=\lambda \overline{\rho_{\mathrm{a}}} \overline{w^{\prime} q^{\prime}}, \\
& H=C_{\mathrm{P}} \overline{\rho_{\mathrm{a}}} \overline{w^{\prime} T^{\prime}}
\end{aligned}
$$

In the general equation presented as Eq. (3), FL is the flux of specific mass, $\rho_{\mathrm{a}}$ is the air density $\left(\mathrm{kg} \mathrm{m}^{-3}\right)$ at a given air temperature, and $\overline{w^{\prime} s^{\prime}}$ is the covariance between the fluctuations in the vertical wind speed $w^{\prime}\left(\mathrm{m} \mathrm{s}^{-1}\right)$ and the fluctuations in a scalar concentration $s^{\prime}$. In particular, when the instantaneous deviation of the specific humidity from mean specific humidity $(q)$, which is denoted $q^{\prime}\left(\mathrm{kg} \mathrm{kg}^{-1}\right)$, is used in the general equation, $E T$ can be derived from Eq. (4). $\lambda$ ET is the latent heat flux $\left(\mathrm{W} \mathrm{m}^{-2}\right)$, and $\lambda$ is the latent heat of water vaporization $\left(\mathrm{J} \mathrm{kg}^{-1}\right)$. The sensible heat fluxes $H$ $\left(\mathrm{W} \mathrm{m}^{-2}\right)$ can also be calculated using the instantaneous deviation of the air temperature $T^{\prime}(\mathrm{K}) . C_{\mathrm{P}}$ is the specific heat of dry air at constant pressure $\left(\mathrm{J} \mathrm{kg}^{-1} \mathrm{~K}^{-1}\right)$.

\subsection{Evapotranspiration measurements and upscaling approaches}

\subsubsection{Evapotranspiration measurements}

The experiment was conducted during summer 2012 in this cotton field. Three sub-periods representing the typical cotton growth stages were selected for comparison analysis of sap flow and eddy covariance analysis, that is, subperiod 1 (SP1) from 23 to 25 July in the flower stage, subperiod 2 (SP2) from 9 to 11 August in the bolling stage, and sub-period 3 (SP3) from 16 to 18 September in the open boll stage. In addition, photosynthesis system measurements were performed on 3 days (i.e., 23 July, 27 July, and $10 \mathrm{Au-}$ gust) to compare with sap flow results. There was no irrigation during these sub-periods and days.

Four sap flow gauges were installed on two wide-row cottons and two narrow-row cottons on the north side of the tower (see Fig. 1). All of the gauges were sampled every $10 \mathrm{~min}$, and data were stored in a CR 1000 data logger (model CR1000, Campbell Scientific, Inc., Logan, UT, USA). Representative plants that had the averaged plant height and leaf area index (LAI) of the field were selected for measurements, and the averaged value of four gauges was used to represent the individual plant transpiration rate. The stem diameter of each gauged plant at $5 \mathrm{~cm}$ above the soil surface was measured every 2 days, and the leaf area of each gauged plant was measured at the time of gauge removal. $P_{\text {in }}$ varied from 80 to $150 \mathrm{~mW}$ due to gauge size, and $K_{\mathrm{ST}}$ was assumed to be $0.54 \mathrm{~W} \mathrm{~m}^{-1} \mathrm{~K}^{-1}$ (Sakuratani, 1984). The value of $K_{\mathrm{SH}}$ was unique to each configuration, with a different gauge and a different stem diameter, and was determined by solving Eq. (2) under the zero flow condition $\left(F_{\mathrm{p}}=0\right)$ using the data obtained each day. Previous studies have assumed that the transpiration should be zero before dawn (Chabot et al., 2005; Dugas et al., 1994; Kigalu, 2007). Such a condition was assumed to be achieved from 03:00 to 05:00 (UTC + 6) in this study, given that sunrise occurred between 05:00 and 06:00 LT during study periods. The stem energy balance method required a steady state and a constant energy input from the heater strip inside the gauge. Therefore, in practice, we installed aluminum bubble foil shields around the gauges to insulate the stem section from changes in the environment.

The EC system was installed $2.25 \mathrm{~m}$ a.g.l. (above ground level) on the stationary tower and maintained at the same height throughout the experiment (cotton canopy height reached $60 \mathrm{~cm}$ on 1 July 2012 and $67 \mathrm{~cm}$ on 30 September 2012). The measurements were conducted at a frequency of $10 \mathrm{~Hz}$, and $30 \mathrm{~min}$-averaged fluxes were computed. Eddy covariance provided continuous ET data for the whole study period.

The LCpro+ photosynthesis system measurements were conducted at 08:00, 10:00, 13:00, 16:00, and 18:00 $(\mathrm{UTC}+6)$ on the 3 days (23 July, 27 July, and 10 August). On these days, LCpro+ was applied to four plants on which sap flow gauges were installed. For each plant, six sunlit leaves located at the top, middle, and bottom layers of the canopy (i.e., two sunlit leaves in each layer) were selected for LCpro+ measurements. Five samples for each leaf were measured and the averaged value was the representative transpiration of this leaf. 
Table 2. The ratio of the sunlit $(\alpha)$ or shaded $(1-\alpha)$ leaf area to the total leaf area and the ratio of transpiration rate of a shaded leaf to that of a sunlit leaf $(\beta)$ at a specific time and canopy layer.

\begin{tabular}{|c|c|c|c|c|c|c|c|c|c|}
\hline \multirow[t]{2}{*}{ Time } & \multicolumn{3}{|c|}{$\begin{array}{c}\text { Top layer } \\
\text { (occupied } 10.1 \% \\
\text { of the leaf area }{ }^{\mathrm{a}} \text { ) }\end{array}$} & \multicolumn{3}{|c|}{$\begin{array}{c}\text { Middle layer } \\
\text { (occupied } 60.5 \% \\
\text { of the leaf area }{ }^{\mathrm{a}} \text { ) }\end{array}$} & \multicolumn{3}{|c|}{$\begin{array}{c}\text { Bottom layer } \\
\text { (occupied } 29.4 \% \\
\text { of the leaf area }{ }^{\mathrm{a}} \text { ) }\end{array}$} \\
\hline & $\alpha^{\mathrm{b}}$ & $1-\alpha$ & $\beta^{\mathrm{b}}$ & $\alpha^{\mathrm{b}}$ & $1-\alpha$ & $\beta^{\mathrm{b}}$ & $\alpha^{\mathrm{b}}$ & $1-\alpha$ & $\beta^{\mathrm{b}}$ \\
\hline 08:00 & 0.29 & 0.71 & 0.55 & 0.21 & 0.79 & 0.44 & 0.17 & 0.83 & 0.26 \\
\hline $10: 00$ & 0.33 & 0.67 & 0.64 & 0.23 & 0.77 & 0.54 & 0.20 & 0.80 & 0.46 \\
\hline $13: 00$ & 0.34 & 0.66 & 0.58 & 0.24 & 0.76 & 0.45 & 0.21 & 0.79 & 0.65 \\
\hline $16: 00$ & 0.29 & 0.71 & 0.39 & 0.21 & 0.79 & 0.46 & 0.17 & 0.83 & 0.34 \\
\hline 18:00 & 0.14 & 0.86 & 0.47 & 0.17 & 0.83 & 0.40 & 0.12 & 0.88 & 0.40 \\
\hline
\end{tabular}

${ }^{\mathrm{a}}$ Zhang et al. (2007); ${ }^{\mathrm{b}}$ Tao (2007).

To understand the variation and uncertainty introduced through LCpro+ measurements and upscaling approaches, a variability analysis of the transpiration at leaf scale at three different levels (i.e., leaf level, layer level and plant level) was conducted in the morning, noon, and afternoon on 23 July. All of the tested leaves were sunlit leaves. At the leaf level, five samples were measured on one typical leaf, and the mean, standard deviation (SD), and coefficient of variation (CV) were calculated based on the five samples. At the layer level, five different leaves in the same canopy layer were selected. The transpiration for each leaf was obtained by averaging five samples. The mean, SD, and CV associated with the layer level were calculated based on the transpiration of the five tested leaves. At the plant level, five different leaves were randomly selected from the whole plant. Additionally, the transpiration for each leaf was obtained by averaging five samples, and the mean, $\mathrm{SD}$, and $\mathrm{CV}$ were calculated based on the transpiration of these five leaves.

\subsubsection{Upscaling approaches}

The inter-comparison of multi-scale ET can validate ET estimates and provide ET components. However, due to the particular spatial scales at which the different ET are measured, as well as the variation in the samples (e.g., leaves and plants), it is necessary to utilize appropriate upscaling approaches before performing the inter-comparison (Evett et al., 2012; Hatton and Wu, 1995).

To obtain ET at the plant scale, transpiration can be simply upscaled from ET at the leaf scale by multiplying the average transpiration rate of a unit leaf area by the total plant leaf area (Approach 1). Due to the enormous variability in leaf transpiration at the plant level, as well as the marked differences in transpiration between shaded and sunlit leaves, this approach is hypothesized to induce significant errors (Petersen et al., 1992).

The ratio of the shaded or sunlit leaves to the total leaves is associated with the canopy structure, and the diurnal trend varies due to sun position in the different canopy layers
(Sarlikioti et al., 2011; Thanisawanyangkura et al., 1997). Therefore, a new upscaling approach (Approach 2) is proposed. This approach incorporates the canopy structure and the relationships between sunlit and shaded leaves, and plant transpiration rate can be calculated based on the following equation:

$$
\begin{aligned}
M_{\mathrm{P}} & =6.48 \times 10^{-3} \sum_{1}^{m}\left\{M_{k} \cdot\left(\alpha_{k} \cdot A_{k}\right)\right. \\
& \left.+\left[\left(M_{k} \cdot \beta_{k}\right) \cdot\left(1-\alpha_{k}\right) \cdot A_{k}\right]\right\},
\end{aligned}
$$

where $M_{\mathrm{P}}$ is the representative plant transpiration rate $\left(\mathrm{g} \mathrm{h}^{-1}\right), m$ is the number of canopy layers (denoted $k, 1$ to $m$ ), $M_{k}$ is the LCpro+ measurement value for the sunlit leaf in layer $k$ (see Eq. 1), $\mathrm{mmol} \mathrm{m}^{-2} \mathrm{~s}^{-1}$ ), $\alpha_{k}$ and $\beta_{k}$ are the ratio of sunlit leaf area to total leaf area and the ratio of transpiration rate of a shaded leaf to that of a sunlit leaf in layer $k$, respectively, $A_{k}$ is the leaf area in layer $k\left(\mathrm{~cm}^{2}\right)$, and $6.48 \times 10^{-3}$ is a unit conversion factor.

In this study, when using Approach 2, the cotton canopy was divided into three layers $(m=3)$, and two sunlit leaves at each layer were selected to be measured. The averaged value was the representative transpiration rate for a sunlit leaf at the indicated layer, whereas the representative transpiration rate for a shaded leaf at this layer was calculated based on the ratio of transpiration rate of a shaded leaf to that of a sunlit leaf (Tao, 2007).

Because we did not measure the parameters of the cotton canopy, we used the typical parameters reported in the literature. A stable canopy structure was formed prior to the measurement days of 23 July, 27 July, and 10 August, thus the canopy structure was assumed to be identical for the analysis (Zhang et al., 2007). Based on the study conducted by Tao (2007) on the physiological properties of shaded and sunlit leaves of cotton, the ratio of the shaded to the sunlit leaves and the ratio of transpiration rate of a shaded leaf to that of a sunlit leaf can be obtained at a specific time and layer (Table 2). 
Traditionally, to obtain field ET from plant scale, we can multiply the average sap flow per plant by the population of plants in the experimental field (Approach 3; for more details, see Dugas et al., 1994). Although we selected the gauged plants as typical representative plants, the limited samples and large variability between the plants results in a large error in the estimation of field ET using this approach (Ham et al., 1990). Reliable field transpiration estimates require additional plant attributes, such as stem diameter and leaf area, to construct a relationship between individual (sap flow) and population (field) transpiration.

Some studies have reported that sap flow is proportional to the stem diameter of a plant (Wilson et al., 2001; Granier et al., 2000). Because the measurement of a stem diameter is a simple and rapid process, we can easily obtain the representative stem diameter for a field and then calculate the representative plant transpiration. The field transpiration can then be directly estimated by multiplying the representative plant transpiration by the plant density (Approach 4; for more details, see Dugas, 1990).

Since transpiration represents the water vapor lost from leaf surfaces, the upscaling approach would be improved if the adjustment of the sap-flow-based ET estimate is based on the leaf area (Heilman and Ham, 1990). However, measurement of the leaf area may require additional work compared with measurement of the stem diameters, and is timeconsuming and impractical if the number of samples is too large. With comprehensive respect to feasibility and accuracy, an integrated upscaling approach of ET from plant- to field scale was developed by Chabot et al. (2005). A relationship (function $A=(D)$ ) between leaf area and stem diameter of sugarcane was developed based on 100 plant samples. Based on the investigations of the stem diameters and the plant densities in $121 \mathrm{~m}$-long sub-plots distributed throughout the field, the total leaf area can be calculated using the abovementioned relationship. The sap flow was expressed per unit leaf area, and the transpiration can then be obtained by multiplying the sap flow per unit leaf area by the total leaf area in the field (Approach 5; for more details, see Chabot et al., 2005).

In consideration of annual crops growing quickly and the relationship between leaf area and stem diameter changing rapidly, Approach 5 is modified to incorporate the temporal variability in the relationship between leaf area and stem diameter to obtain Approach 6. The different relationships between leaf area and stem diameter $A_{j}=f_{j}\left(D_{j}\right)$ are used for different cotton growth stages $j$ in Approach 6. The total leaf area in the field can be estimated using the following equation:

$A_{\text {total }, j}=f_{j}\left(\overline{D_{j}}\right) \cdot n$,

where $A_{\text {total }}$ is total leaf area $\left(\mathrm{cm}^{2}\right)$ in the experimental field and $n$ represents the number of plants.
The sap flow is assumed to be proportional to the leaf area; hence, field transpiration rate $E_{\mathrm{SF}}$ can be calculated by the following equation:

$E_{\mathrm{SF}}=\frac{F_{\mathrm{p}}}{A_{\mathrm{g}}} \cdot \frac{A_{\text {total }}}{1000 Q}$

where $E_{\mathrm{SF}}$ is the field transpiration rate derived from the sap flow measurements $\left(\mathrm{mm} \mathrm{h}^{-1}\right), F_{\mathrm{p}}$ is the plant sap flow rate $\left(\mathrm{g} \mathrm{h}^{-1}\right), A_{\mathrm{g}}$ is leaf area of the plant on which sap flow measurements are performed $\left(\mathrm{cm}^{2}\right), Q$ is the field area $\left(\mathrm{m}^{2}\right)$, and 1000 is a unit conversion factor.

Using the similar approach, the field transpiration $E_{\mathrm{PS}}$ $\left(\mathrm{mm} \mathrm{h}^{-1}\right)$ can also be obtained from the LCpro+ measurements through the following equation, the results of which are presented in Sect. 3.3.5 for comparison:

$E_{\mathrm{PS}}=\frac{M_{\mathrm{P}}}{A_{\mathrm{g}}} \cdot \frac{A_{\text {total }}}{1000 Q}$.

Through the use of upscaling approaches, ET results measured using different methods can be compared at plant or field scale.

\subsection{Other measurements}

In addition to the ET measurements described above, soil moisture and crop attributes (e.g., leaf area and stem diameter) were also measured in this study. Thirty soil sensors (three models, i.e., Hydra Probe, Stevens Water Monitoring System, Inc., Beaverton, OR, USA; Digital TDT, Acclima Inc., Meridian, ID, USA; CS616, Campbell Scientific Inc., Logan, UT, USA) were placed in the wide-row, narrow-row, and inter-film zones at $0.05,0.10,0.15,0.20,0.30,0.40,0.50$, $0.60,0.70$, and $0.80 \mathrm{~m}$ below the ground to obtain a general view of field soil water condition. The data were stored every 5 min in a CR1000 data logger.

In order to obtain the relationships between leaf area and stem diameter $A_{j}=f_{j}\left(D_{j}\right)$ used in Approach 6, 10 typical cotton plants of an averaged size (compared with the plants throughout the field) were randomly selected for the leaf area measurements every 2 weeks and stem diameters of selected plants were recorded at the same time. All of the leaves were stripped from each plant, and the leaf area was then obtained by directly scanning all of the leaves using a leaf area meter (model Yaxin-1241, Beijing Yaxinliyi Science and Technology Co., Ltd., China). The LAI was calculated by dividing the leaf area by the area that each plant occupied.

The plant density and cotton stem diameters were investigated inside 100 sub-plots of the Eastern Field on 1 July and 12 September. We selected six $0.6 \mathrm{~m}^{2}$ quadrats distributed throughout each sub-plot to count the number of plants, and we measured the stem diameters of 20 plants in each subplot. The dynamic change of stem diameter was measured with 10 fixed plants (typical ones with the averaged plant height and LAI of the whole field) located in the Eastern 
Table 3. Variability in transpiration at the leaf scale on 23 July 2012.

\begin{tabular}{|c|c|c|c|c|c|c|c|c|c|}
\hline \multirow{2}{*}{$\begin{array}{l}\text { Time } \\
\text { Level of analysis }\end{array}$} & \multicolumn{3}{|c|}{ Morning (07:30-08:30) } & \multicolumn{3}{|c|}{ Noon (11:30-12:30) } & \multicolumn{3}{|c|}{ Afternoon (16:30-17:30) } \\
\hline & Leaf & Layer & Plant & Leaf & Layer & Plant & Leaf & Layer & Plant \\
\hline $\operatorname{Mean}\left(\mathrm{mm} \mathrm{h}^{-1}\right)$ & 1.09 & 1.07 & 0.75 & 1.68 & 1.87 & 1.39 & 1.14 & 1.15 & 1.09 \\
\hline Standard deviation $\left(\mathrm{mm} \mathrm{h}^{-1}\right)$ & 0.04 & 0.14 & 0.22 & 0.06 & 0.34 & 0.38 & 0.05 & 0.19 & 0.40 \\
\hline Coefficient of variation $(\%)$ & 3.63 & 12.85 & 29.09 & 3.28 & 17.96 & 27.58 & 4.74 & 16.94 & 36.30 \\
\hline
\end{tabular}

Field every 2 weeks during cotton growth period. In addition, all stem diameters were measured at $5 \mathrm{~cm}$ above the soil surface.

\section{Results}

\subsection{Meteorological conditions}

The meteorological conditions during the study period, including air temperature, net radiation, vapor pressure deficit (VPD), and wind speed, are shown in Fig. 3. The air temperature and net radiation were considerably higher during SP1 and SP2 than during SP3, whereas the VPD and wind speed showed no significant difference among the three subperiods. In addition, no precipitation occurred on these days.

Frequent drip irrigation at 5- to 10-day intervals was implemented during July and August (see Table 1) and resulted in high air relative humidity in SP1 and SP2 with a value of approximately $50 \%$. Because irrigation was terminated in September, the soil surface became dry, and the air relative humidity dropped to $34 \%$ in SP3. However, the VPD during these three sub-periods did not change significantly due to the change of saturation vapor pressure, which was lowest in SP3.

The 3 days (23 July, 27 July, and 10 August) that were chosen for the LCpro+ measurements were sunny days with the highest net radiation. In contrast, on cloudy days, such as 24 July, 25 July, and 9 August, the net radiation was relatively low.

\subsection{Comparison at the plant scale}

\subsubsection{Variability in transpiration at the leaf scale}

The variability analysis results at the leaf scale are shown in Table 3. The CVs at different times (morning, noon, and afternoon) reveal the consistent trend obtained for each level of analysis. The averaged CV at the leaf level, which had a magnitude of $3.89 \%$, is hypothesized to reflect the random error. The CV at the layer level, which had an averaged value of $15.91 \%$, was greater than that at the leaf level and less than that at the plant level. Regardless of the different transpiration rates between sunlit and shaded leaves, the $\mathrm{CV}$ of the whole plant was $30.99 \%$, which suggests a large variability in the leaf transpiration rate throughout the plant. In addition,
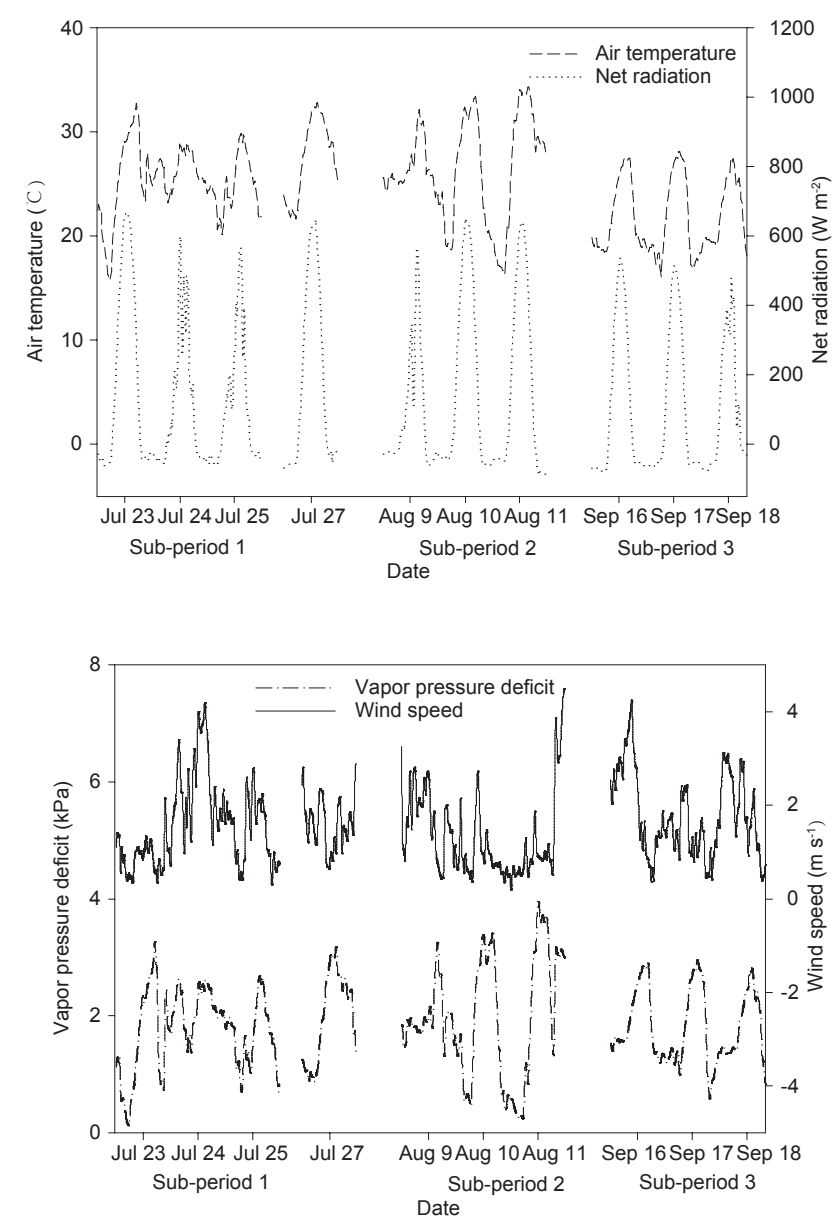

Fig. 3. Diurnal trends of air temperature, net radiation, vapor pressure deficit, and wind speed measured $2.25 \mathrm{~m}$ above the ground.

the difference in the transpiration rate between a sunlit leaf and a shaded leaf can be significant, e.g., as high as fourfold at 8 a.m. (Tao, 2007).

\subsubsection{Upscaling from the leaf to the plant scale}

Based on the upscaling approaches from leaf to plant scale and the data obtained from the measurements and literature, the scaled plant transpiration can be determined using Approaches $1\left(M_{\mathrm{S}}\right)$ and $2\left(M_{\mathrm{p}}\right)$ (Table 4$)$. In general, the value of $M_{\mathrm{s}}$ was as high as 1.69 -fold of $M_{\mathrm{p}}$. In consideration of the 
Table 4. Plant transpiration derived using Approach $1\left(M_{\mathrm{S}}\right)$ and Approach $2\left(M_{\mathrm{p}}\right)$.

\begin{tabular}{crrrrrrrr}
\hline Date & \multicolumn{2}{c}{$23 \mathrm{Jul}$} & & \multicolumn{2}{c}{$27 \mathrm{Jul}$} & & \multicolumn{2}{c}{$10 \mathrm{Aug}$} \\
\cline { 2 - 3 } \cline { 8 - 9 } \cline { 7 - 8 } Time & $M_{\mathrm{S}}\left(\mathrm{g} \mathrm{h}^{-1}\right)$ & $M_{\mathrm{p}}\left(\mathrm{g} \mathrm{h}^{-1}\right)$ & & $M_{\mathrm{S}}\left(\mathrm{g} \mathrm{h}^{-1}\right)$ & $M_{\mathrm{p}}\left(\mathrm{g} \mathrm{h}^{-1}\right)$ & & $M_{\mathrm{S}}\left(\mathrm{g} \mathrm{h}^{-1}\right)$ & $M_{\mathrm{p}}\left(\mathrm{g} \mathrm{h}^{-1}\right)$ \\
\hline $08: 00$ & 95.17 & 47.32 & & \multicolumn{2}{c}{ Data missing } & & 82.91 & 44.53 \\
$10: 00$ & 164.83 & 110.06 & & 156.82 & 100.82 & & 107.64 & 67.33 \\
$13: 00$ & 168.27 & 106.28 & & 121.19 & 75.38 & & 174.29 & 103.65 \\
$16: 00$ & 101.35 & 59.76 & & 135.15 & 75.54 & & 148.53 & 84.44 \\
$18: 00$ & 53.39 & 26.42 & & 30.55 & 13.79 & & 54.11 & 26.77 \\
\hline
\end{tabular}

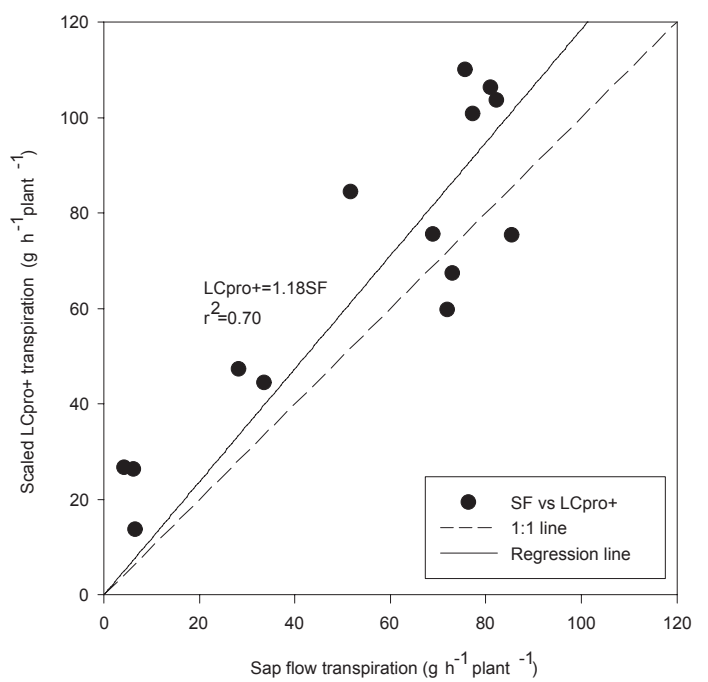

Fig. 4. Correlation between the transpiration measured by sap flow and the scaled transpiration of LCpro+ measurements on 23 July, 27 July, and 10 August.

difference between the sunlit and shaded leaves, Approach 1 takes all the leaves as sunlit ones, and likely overestimates plant transpiration.

\subsubsection{Comparison of sap flow and the scaled LCpro+ measurements}

The scaled transpiration obtained using Approach $2\left(M_{\mathrm{P}}\right)$ was compared with the results measured through sap flow $\left(F_{\mathrm{P}}\right)$ for the same cotton plants. The results are shown in Fig. 4. In general, the value of $M_{\mathrm{P}}$ was slightly higher than that of $F_{\mathrm{P}}$, and the slope of the regression line was 1.18 $\left(r^{2}=0.70\right)$. Biases clearly existed when the transpiration rate was too low or too high, which indicates that the LCpro+ measurement may most likely disturb the normal status of leaf transpiration due to contact. In contrast, the comparison of Approach 1 results and sap flow measurements resulted in slope and $r^{2}$ values of 1.94 and 0.52 , respectively (data not shown in Fig. 4, see Table 5). Thus, Approach 2 exhibits significantly improved upscaling results.
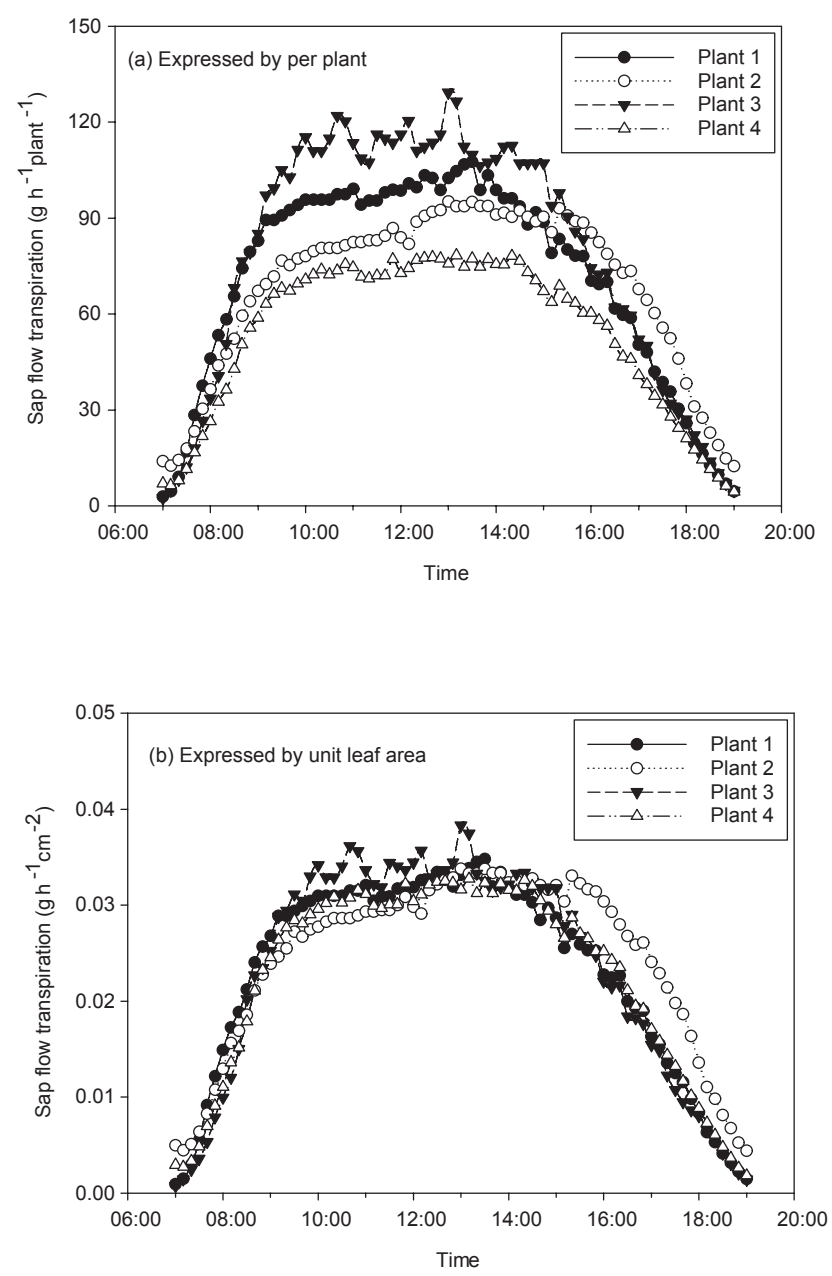

Fig. 5. Transpiration estimates based on sap flow and expressed by unit leaf area and per plant.

\subsection{Comparison at the field scale}

\subsubsection{Variability in transpiration at the plant scale}

Large differences in the plant transpiration were observed among four plants that were gauged based on sap flow (Fig. 5a). On 9 July, the cumulative sap flows obtained for plants 1 through 4 were $866,840,959$, and $659 \mathrm{gday}^{-1}$, 
Table 5. The slope and coefficient of determination $\left(r^{2}\right)$ for the different upscaling approaches.

\begin{tabular}{|c|c|c|c|c|c|c|}
\hline \multicolumn{2}{|c|}{ Upscaling approach } & \multirow{2}{*}{$\begin{array}{l}\text { Equation } \\
\text { LCpro+ }=1.94 \mathrm{SF}\end{array}$} & \multirow{2}{*}{$\begin{array}{l}\text { Slope } \\
1.94\end{array}$} & \multirow{2}{*}{$\begin{array}{l}r^{2} \\
0.52\end{array}$} & \multirow{2}{*}{$\begin{array}{l}\text { Brief description } \\
\text { Total leaf area and uniform transpiration }(T) \text { rate }\end{array}$} & \multirow{2}{*}{$\begin{array}{c}\begin{array}{c}\text { Error analysis } \\
\left(\frac{\sigma_{M_{\mathrm{P}}}}{M_{\mathrm{P}}} \text { or } \frac{\sigma_{E_{\mathrm{SF}}}}{E_{\mathrm{SF}}}\right)^{*}\end{array} \\
0.311\end{array}$} \\
\hline From leaf- to plant scale & Approach 1 & & & & & \\
\hline & Approach 2 & LCpro $+=1.18 \mathrm{SF}$ & 1.18 & 0.70 & Canopy structure, sunlit and shaded leaves & 0.161 \\
\hline \multirow[t]{4}{*}{ From plant- to field scale } & Approach 3 & $\mathrm{SF}=1.61 \mathrm{EC}$ & 1.61 & 0.88 & Plant population $(\mathrm{PP})$ & 0.156 \\
\hline & Approach 4 & $\mathrm{SF}=1.31 \mathrm{EC}$ & 1.31 & 0.88 & $\mathrm{PP}, T$ is proportional to the stem diameter (SD) & 0.123 \\
\hline & Approach 5 & $\mathrm{SF}=1.33 \mathrm{EC}$ & 1.33 & 0.87 & $\begin{array}{l}\mathrm{PP}, T \text { is proportional to the leaf area (LA), } \\
\text { Fixed relationship between LA and SD }\end{array}$ & 0.113 \\
\hline & Approach 6 & $\mathrm{SF}=1.10 \mathrm{EC}$ & 1.10 & 0.87 & $\begin{array}{l}\mathrm{PP}, \mathrm{T} \text { is proportional to } \mathrm{LA} \text {, } \\
\text { Dynamic relationship between LA and SD }\end{array}$ & 0.073 \\
\hline
\end{tabular}

${ }^{*} M_{\mathrm{P}}$ is upscaled plant transpiration, $E_{\mathrm{SF}}$ is upscaled field transpiration, $\sigma_{M_{\mathrm{P}}}$ and $\sigma_{E_{\mathrm{SF}}}$ are the standard error for $M_{\mathrm{P}}$ and $E_{\mathrm{SF}}$, respectively.

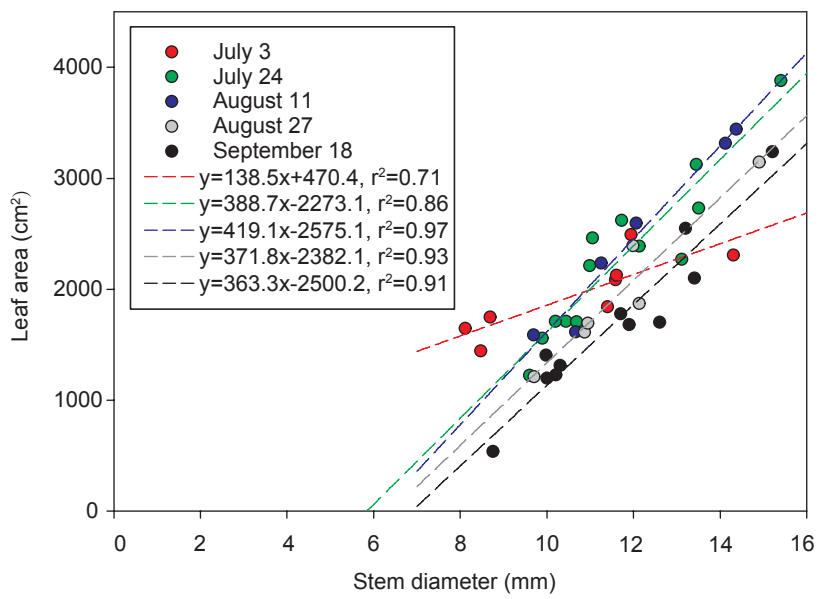

Fig. 6. Relationships between leaf area and stem diameter.

respectively. The mean cumulative sap flow was $831 \mathrm{~g} \mathrm{day}^{-1}$ with a coefficient of variation of $15.11 \%$.

Because the sap flow was expressed per unit leaf area (Fig. 5b), the errors were markedly reduced (Heilman and Ham, 1990). The cumulative sap flows per unit leaf area on 9 July for plants 1 through 4 were $0.280,0.299,0.284$, and $0.275 \mathrm{~g} \mathrm{~cm}^{-2}$ day $^{-1}$, respectively. The mean cumulative sap flow was $0.285 \mathrm{~g} \mathrm{~cm}^{-2} \mathrm{day}^{-1}$ with a coefficient of variation of $3.53 \%$. The results are consistent with the findings reported by Ham et al. (1990), who observed sap flow CV values expressed per plant and unit leaf area of 13 and $7.7 \%$, respectively. The results indicate that, although the measurements of the leaf area may require additional work, they may reduce the number of devices required to represent the field condition and are thus worth the effort (Dugas, 1990). Therefore, it is necessary to account for plant variability in sap flow measurements, even in homogenous cotton farmland.

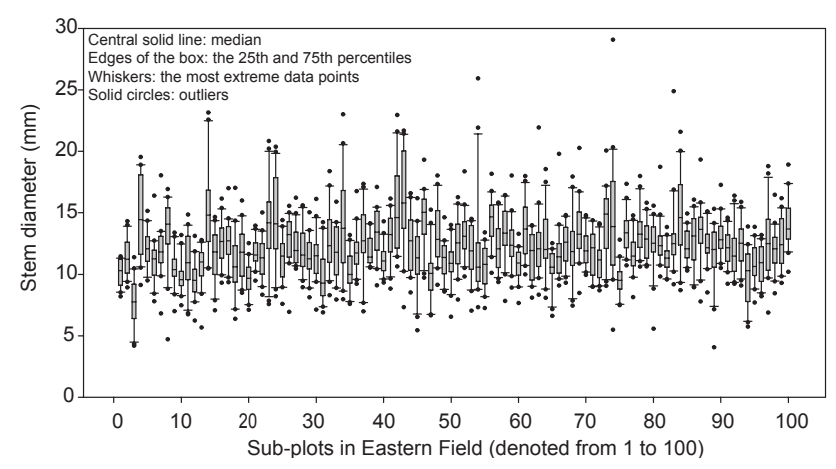

Fig. 7. Stem diameter variability in 100 sub-plots located in the Eastern Field on 12 September 2012.

\subsubsection{Upscaling from the plant to the field scale}

When using Approach 6, a series of relationships $A_{j}={ }_{j}\left(D_{j}\right)$ with correlation coefficients $\left(r^{2}\right)$ ranging from 0.71 to 0.97 were developed based on the experiments to represent different cotton growth stages $j$, including the three sub-periods (Fig. 6). The slope increased rapidly from 3 to 24 July, which suggests that the leaf area changed rapidly in July. The slope was then fairly stable throughout the remaining growth period, whereas the intercept gradually became small over time, which demonstrates that the rate of defoliation gradually exceeded the rate of leaf area growth.

As described in Sect. 2.4, 2000 plants were randomly selected from 100 sub-plots (denoted $i$ from 1 to 100) in the Eastern Field to determine the plant stem diameter at the end of the cotton growth period on 12 September 2012 (Fig. 7). The average value of the stem diameter was $12.18 \mathrm{~mm}$, and the standard deviation was $2.64 \mathrm{~mm}$, which suggests a notable variability $(\mathrm{CV}=21.7 \%)$ among the plants under growth conditions. In addition, the dynamic changes in stem diameters measured by 10 fixed plants every 2 weeks are illustrated in Fig. 8. The cotton stem grew rapidly in the vegetative stage after seed germination, and became stable in the 
Table 6. Upscaled field transpiration derived through Approach $6\left(E_{\mathrm{SF}}, \mathrm{mm} \mathrm{day}^{-1}\right)$ and Approach $3\left(E_{\mathrm{S}}, \mathrm{mm} \mathrm{day}^{-1}\right)$.

\begin{tabular}{lcclcclcc}
\hline Sub-period 1 & $E_{\mathrm{SF}}$ & $E_{\mathrm{S}}$ & Sub-period 2 & $E_{\mathrm{SF}}$ & $E_{\mathrm{S}}$ & Sub-period 3 & $E_{\mathrm{SF}}$ & $E_{\mathrm{S}}$ \\
\hline 23 Jul & 5.88 & 8.97 & 9 Aug & 3.42 & 5.43 & $16 \mathrm{Sep}$ & 3.36 & 4.78 \\
24 Jul & 4.72 & 7.21 & $10 \mathrm{Aug}$ & 5.54 & 8.76 & $17 \mathrm{Sep}$ & 3.35 & 4.81 \\
25 Jul & 4.62 & 7.10 & $11 \mathrm{Aug}$ & 5.31 & 8.41 & $18 \mathrm{Sep}$ & 2.67 & 3.86 \\
\hline
\end{tabular}

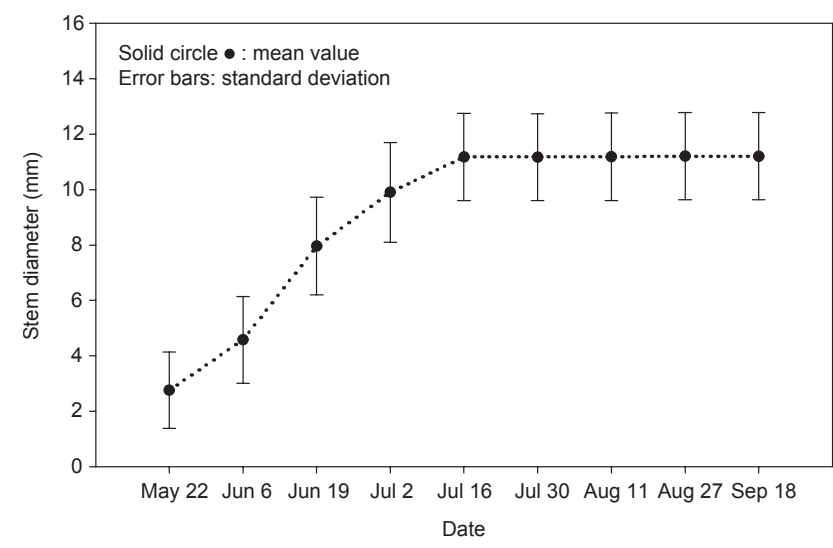

Fig. 8. Dynamic changes in the stem diameter. The stem diameters of 10 fixed plants were measured every 2 weeks.

reproductive stage after 16 July. Therefore, we can predict the stem diameter $\left(D_{i}, \mathrm{~mm}\right)$ for any of the cotton growth stages based on the data shown in Figs. 7 and 8.

The number of plants $n_{i}$ in each sub-plot was counted on six random $0.6 \mathrm{~m}^{2}$ quadrats. Based on the dynamic relationships between the stem diameter and the leaf area, as well as the stem diameter distribution, we can obtain the leaf area distribution in the field for a specific time during the cotton growth period using Eq. (7). For instance, the results of the leaf area index distribution in the Eastern Field on $11 \mathrm{Au}-$ gust 2012 are shown in Fig. 9.

Based on sap flow measurements and total leaf area of the field, we can obtain the scaled field transpiration $\left(E_{\mathrm{SF}}\right)$ using Approach 6. The results are shown in Table 6. The transpiration derived from Approach $3\left(E_{\mathrm{S}}\right)$ was higher than $E_{\mathrm{SF}}$ by a factor of 1.52 , which indicates that the gauged plants were probably stronger than the representative plant size. The results agree with those reported by Ham et al. (1990), who observed that $E_{\mathrm{S}}$ was as high as 1.63 -fold of $E_{\mathrm{SF}}$. The results derived from the other approaches are not shown in Table 6.

\subsubsection{Energy balance closure of eddy covariance}

Energy balance closure is one approach that can be used to evaluate the reliability of eddy covariance (EC) measurements (Wilson et al., 2002). Using all valid half-hourly data in the three sub-periods (data points, $n=399$ ), the slope between the available energy flux $\left(R_{n}-G\right)$ and the sum of sensible and latent heat fluxes $(\mathrm{LE}+H)$ for this site was 0.70 ,

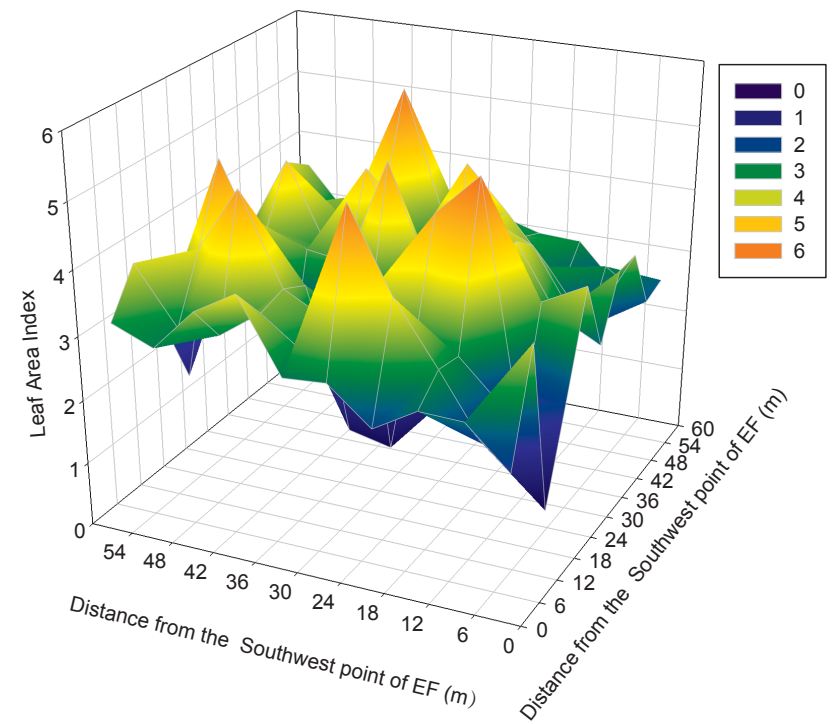

Fig. 9. Example of leaf area index (LAI) distribution in the Eastern Field (EF) on 11 August 2012.

the intercept was $8.01 \mathrm{~W} \mathrm{~m}^{-2}$, and the coefficient of determination $\left(r^{2}\right)$ was 0.90 , as shown in Fig. 10. The reasons underlying the energy imbalance has been investigated by numerous researchers over the past few decades (Franssen et al., 2010; Leuning et al., 2012; Stoy et al., 2013); however, these are complicated and not yet fully understood.

Under mulched drip irrigation, general factors accounting for the lack of energy balance closure, including the mismatch in the source area for different measurements, sampling errors, systematic bias, neglected energy sinks (e.g., energy storage in cotton biomass), the loss of low/highfrequency contributions to the turbulent flux, and neglected advection of scalars, still make sense. However, the plastic mulching film likely increases the probability and magnitude of the imbalance (Ding et al., 2010; Zhou et al., 2011). The study conducted by Zhou et al. (2011), who analyzed mulched drip irrigation in a cotton field, suggested that the turbulent fluxes $(\mathrm{LE}+H)$ could be blocked by more than $11 \%$ relative to the available energy $\left(R_{n}-G\right)$ due to the impact of mulch. If this is true, the slope between $\left(R_{n}-G\right)$ and $(\mathrm{LE}+H)$ will increase to 0.81 (present closure of 0.70 plus 0.11 ) in this study, which is promising based on the previously obtained values of $0.53-0.99$ for the energy closure (Wilson et al., 2002). Thus, we are confident that the eddy 


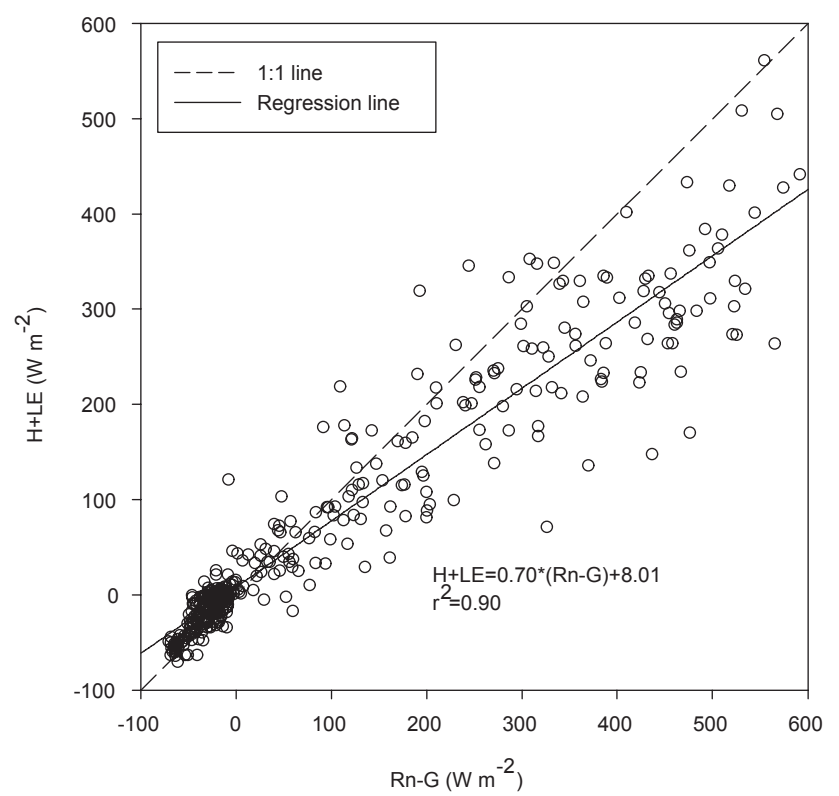

Fig. 10. Energy balance closure of eddy covariance. The data are paired $30 \mathrm{~min}$ averages collected during the three sub-periods.

covariance measurements provide an accurate ET estimate at this site.

\subsubsection{Comparison of eddy covariance and the scaled sap flow and LCpro+ measurements}

In general, drip irrigation systems deliver the limited amount of water directly to the plant root zone; consequently, the soil water content (SWC) in the inter-film zone is very low (Bonachela et al., 2001). In addition, the mulched film eliminates soil evaporation in the wide-row and narrow-row zones (Wang et al., 2001). Therefore, the soil evaporation is expected to be a small portion of ET under mulched drip irrigation, especially when irrigation is stopped for a long time. In this study, LCpro+ measurements were used to measure the bare soil evaporation in the inter-film zone when the soil pot was substituted for the leaf chamber on 20 September ( 2 days after SP3, no irrigation for 23 days, $\mathrm{SWC}=15.5 \%$ within a depth of $20 \mathrm{~cm}$ ). The measured value was only $0.04 \mathrm{~mm} \mathrm{day}^{-1}$. Therefore, we assume that soil evaporation was sufficiently small in SP3 so that it can be neglected. In other words, evapotranspiration measured by eddy covariance in SP3 contained the transpiration component only. Thus, in this study, SP3 was chosen as the period for transpiration comparison at the field scale.

Based on the four upscaling approaches described in Sect. 2.3.2, the correlations between $E_{\mathrm{SF}}$ and $E_{\mathrm{EC}}$ values were analyzed for SP3. At times, the wind blew from the back of the 3-D sonic anemometer, and the flow distortion caused by the anemometer's arms and other supporting structures was considerable and may have resulted in an

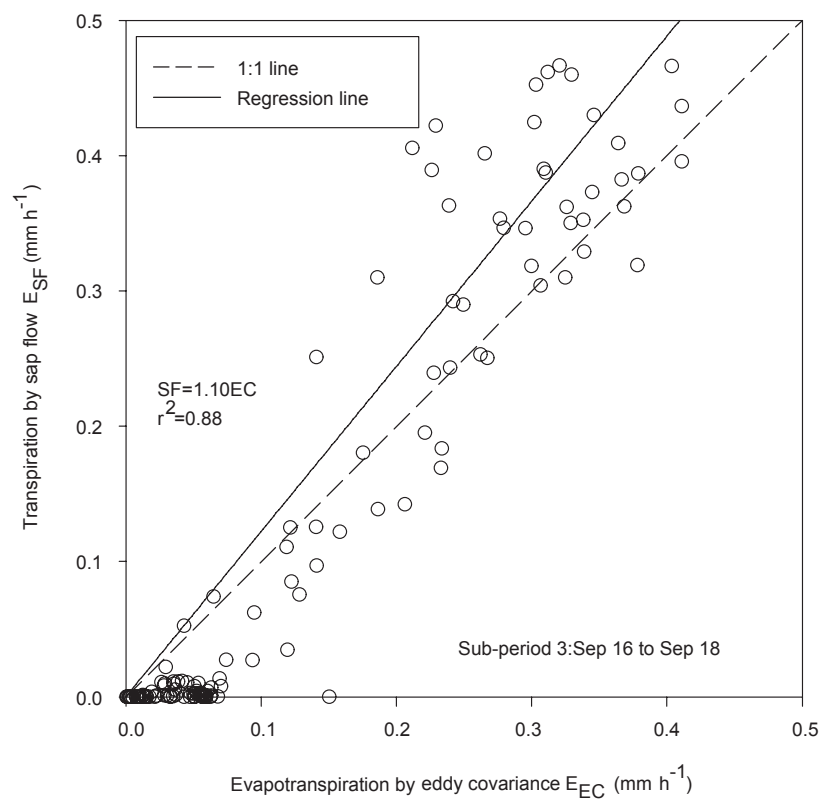

Fig. 11. Correlation between transpiration obtained from the upscaling of the sap-flow-based measurement (Approach 6; $E_{\mathrm{SF}}$ ) and ET obtained through eddy covariance $\left(E_{\mathrm{EC}}\right)$ for sub-period 3 .

underestimation of ET (van Dijk et al., 2004). Therefore, the data obtained when the wind blew from the back of the 3-D sonic anemometer were excluded in our correlation analysis.

The slopes of the regression line were 1.61, 1.31, 1.33, and 1.10 for Approaches 3 through 6, respectively (Table 5). Approach 6 improves the upscaling results significantly. Figure 11 shows a pronounced qualitative similarity for the transpiration obtained through sap flow (Approach 6) $\left(E_{\mathrm{SF}}\right)$ and through eddy covariance $\left(E_{\mathrm{EC}}\right)$, which confirms that Approach 6 is a reasonable upscaling approach.

The diurnal trends of the transpiration estimates obtained by sap flow (Approach $6 ; E_{\mathrm{SF}}$ ) and by eddy covariance $\left(E_{\mathrm{EC}}\right)$ are shown in Fig. 12 for SP3. For convenience, the potential evapotranspiration calculated using the FAO PenmanMonteith equation $\left(E_{\mathrm{P}}\right.$; Allen et al., 1998) is also shown in this figure. The $E_{\mathrm{SF}}$ and $E_{\mathrm{EC}}$ matched $E_{\mathrm{P}}$ well, which suggests that the instruments can respond well to changes in the meteorological conditions of the surrounding environment. Also, the coincidence between potential evaporation $\left(E_{\mathrm{P}}\right)$ and measured transpiration shows that the two independent methods can get the similar values for the well-watered crop, which further implies the rationality of our measurements. On 17 September, due to distortion by the anemometer's arms and other supporting structures, $E_{\mathrm{EC}}$ was obviously less than $E_{\text {SF }}$.

The results prove that Approach 6, which takes dynamic relationships between leaf area and stem diameter into account, is advanced and reasonable. Using this upscaling approach to obtain field transpiration, the evapotranspiration components are analyzed in the following section. 


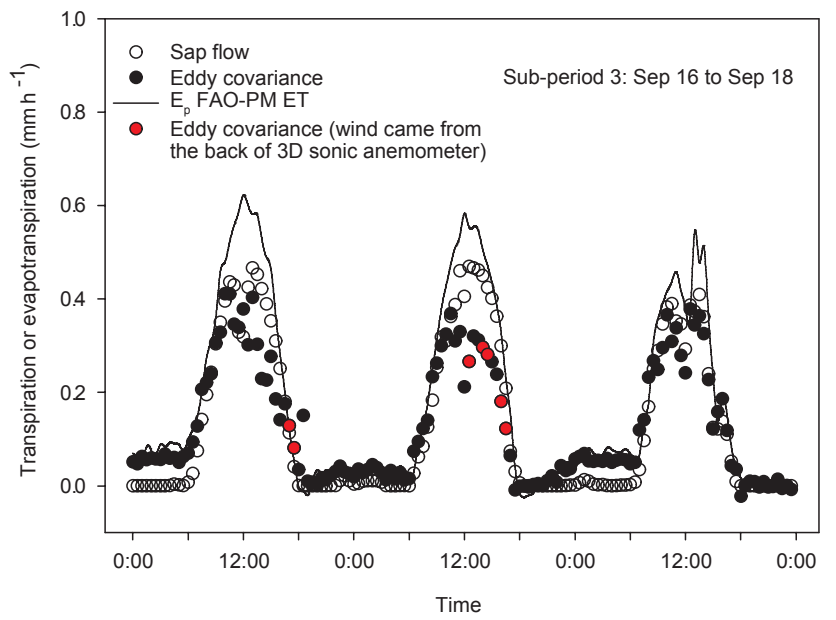

Fig. 12. Diurnal trends of transpiration derived from the upscaling of the sap flow measurements (Approach 6) and measured by eddy covariance during sub-period 3.

\subsubsection{Evapotranspiration components under mulched drip irrigation conditions}

The partitioning of the evapotranspiration flux is important for understanding the water exchange and optimizing water management in arid and semi-arid areas. In previous studies, the stable isotope technique has been widely applied to the evapotranspiration partitioning (Wang et al., 2010, 2013). Meanwhile, the difference between $E_{\mathrm{EC}}$ and $E_{\mathrm{SF}}$ also provides one useful approach for partitioning these fluxes and reflects the contribution of soil evaporation to the total ET within the flux footprint of eddy covariance (Williams et al., 2004; Wilson et al., 2001).

As described in Sect. 3.3.4, soil evaporation can be neglected in SP3 due to the dry soil surface in the interfilm zone $(\mathrm{SWC}=15.6 \%$ within a depth of $20 \mathrm{~cm})$, the relatively low evaporative demand $\left(E_{\mathrm{P}}=4.396 \mathrm{~mm} \mathrm{day}^{-1}\right)$, and the fully closed canopy. Therefore, the difference between $E_{\mathrm{SF}}$ and $E_{\mathrm{EC}}$ in SP3 was regarded as a systematic error induced by both inherent error of methods (i.e., underestimate/overestimate of $T$ and ET) and upscaling approaches. Since the measurements and upscaling approaches were completely identical in the three sub-periods, the systematic error of SP3 could be consistent with that observed for the other two sub-periods. The systematic error in SP1 and SP2 was then overcome by using SP3 to calibrate the sap flow. We recalculated all of the upscaled sap flow data in SP1 and SP2 using the regression model between $E_{\mathrm{EC}}$ and $E_{\mathrm{SF}}$ derived from SP3 (Transpiration $=0.737 \times$ [upscaled sap flow $]+0.035$ ). After the recalculation, the soil evaporation under mulched drip irrigation in this region can be evaluated by the difference between $E_{\mathrm{EC}}$ and the recalculated $E_{\mathrm{SF}}$. This method was adopted and proved to be valid in the
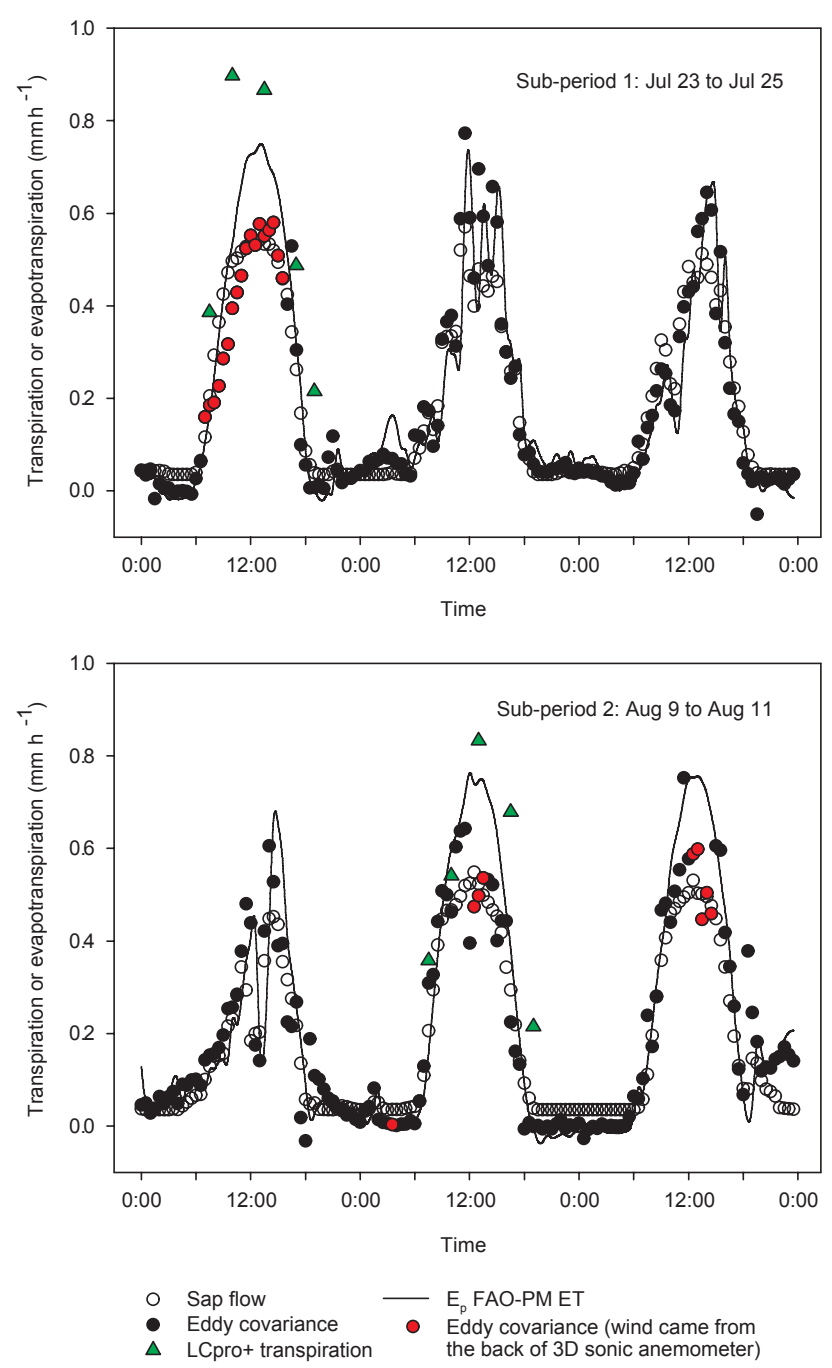

Fig. 13. Diurnal trends of transpiration determined by sap flow measurements (upscaled using Approach 6 and calibrated), the LCpro+ photosynthesis system (upscaled using Approach 2), and evapotranspiration determined by eddy covariance during sub-periods 1 and 2 .

study conducted by Williams et al. (2004) in an olive orchard (Williams et al., 2004).

The diurnal trends of evapotranspiration after upscaling and calibration are shown in Fig. 13. As shown in this figure, $E_{\mathrm{EC}}$ was fairly high in SP1 and SP2, reaching up to $0.7 \mathrm{~mm} \mathrm{~h}^{-1}$ at noon due to the favorable soil moisture conditions, high LAI and evaporation potential. In contrast, the ET value was only $0.4 \mathrm{~mm} \mathrm{~h}^{-1}$ at noon in SP3. The gap between $E_{\mathrm{EC}}$ and $E_{\mathrm{SF}}$ was the component of soil evaporation. At noon, the soil evaporation was appreciable, whereas it was quite small at night. We also plot the data obtained by applying LCpro+ on 23 July and 10 August in this figure. The results show that $E_{\mathrm{PS}}$ was higher than $E_{\mathrm{EC}}$ most of the time, which is consistent with the conclusion obtained in Sect. 3.2.3. 
Figure 14 shows the correlation between transpiration obtained from sap flow measurement (after upscaling and calibration) and ET obtained through eddy covariance. Evapotranspiration by EC and transpiration by sap flow agree well for low- and mid-rates, but disagree for higher flux rates. There may be two potential reasons to explain this phenomenon: the soil evaporation was probably more intense at noon due to the higher temperature and radiation, or there was a saturation level for plant transpiration above which transpiration stayed constant and more evaporation occurred. However, it is still not clear based on this study.

In general, the slopes were 0.871 and 0.823 for SP1 and $\mathrm{SP} 2$ in Fig. 14 , that is, $T / \mathrm{ET}\left(E_{\mathrm{SF}} / E_{\mathrm{EC}}\right)$ was 87.1 and $82.3 \%$ for these two sub-periods, respectively. The results suggested that the fraction of soil evaporation to evapotranspiration was greater in SP2 than in SP1. This difference might be due to the fact that soil water content (SWC), which significantly affected soil evaporation in the cotton growth period, was higher in SP2 than in SP1 due to drip irrigation (Table 7). In fact, irrigation occurred more than one week before 23 July ( $33.26 \mathrm{~mm}$ irrigation on $15 / 16 \mathrm{July}$ ). In contrast, $59.28 \mathrm{~mm}$ drip irrigation was implemented on 8 August, which was only one day before SP2. The magnitudes of the soil evaporation were $0.508 \mathrm{~mm} \mathrm{day}^{-1}$ in SP1 and $0.801 \mathrm{~mm} \mathrm{day}^{-1}$ in SP2. The results confirm that transpiration constitutes the largest portion of ET under mulched drip irrigation when the canopy is closed and provide quantitative estimates of the soil evaporation before (SP1) and after (SP2) irrigation at this site during the cotton flower and bolling stages. However, the results of ET components are only based on the short period observation. More data is needed if the fraction of transpiration over ET for the whole cotton growth period is to be determined.

\subsection{Error analysis}

In order to assess the flux uncertainties, and clarify how instrument precision, vegetative measurements and calculation theory affect the uncertainties (Good et al., 2012), the error analysis of upscaling approaches (Approach 1 to 6) are implemented in this section. Using the consistent manner, the error of soil evaporation estimate is also explored. It is worth noting that since the true values of evapotranspiration are inaccessible, the error analysis below is only based on the standard error, representing the variation relative to the mean, and is not an indication of measurement accuracy.

\subsubsection{Plant scale}

The plant transpiration is calculated by the following equation in Approach 1:

$M_{\mathrm{P}}=M \cdot A_{\text {plant }}$,

where $M$ is the transpiration rate for the sunlit leaf by the LCpro+ measurement, and $A_{\text {plant }}$ is leaf area of the plant.
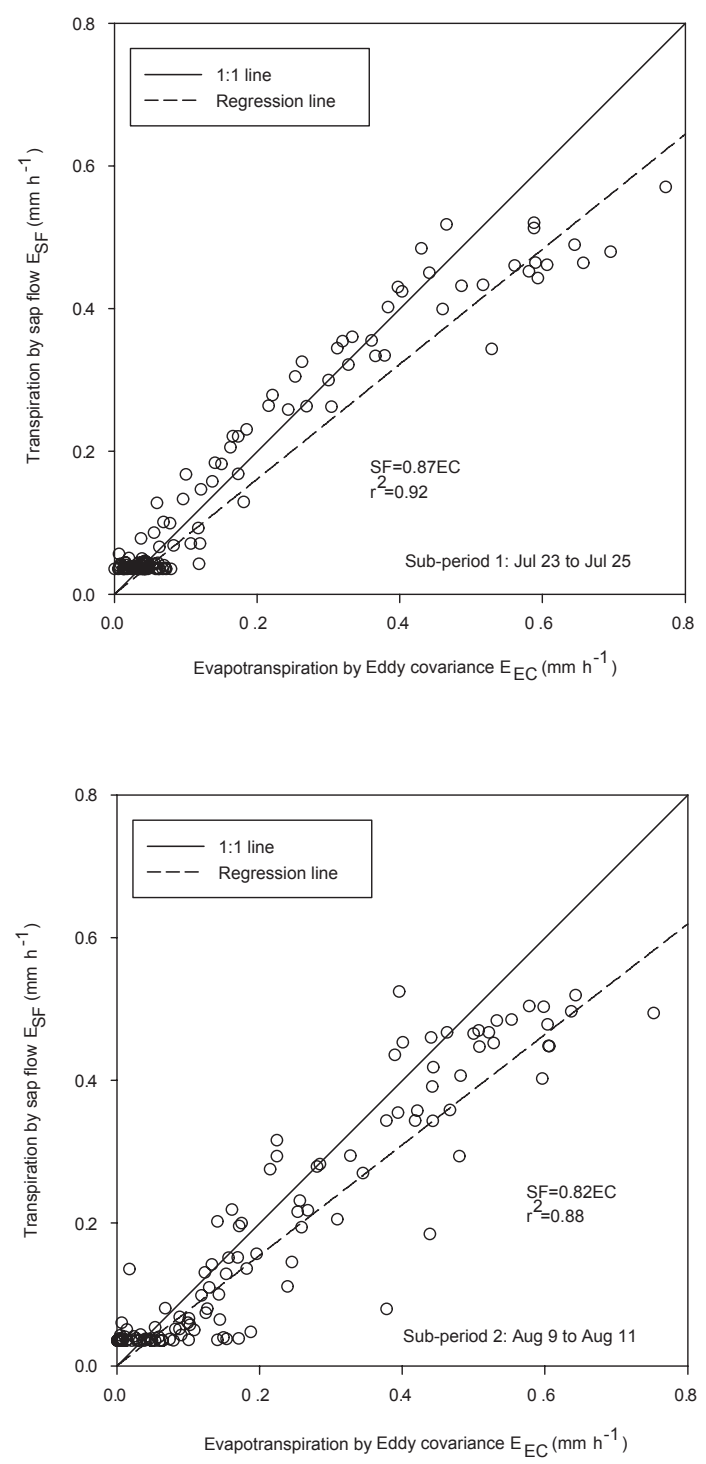

Fig. 14. Correlation between the transpiration obtained through sap flow measurements (upscaled using Approach 6 and calibrated; $\left.E_{\mathrm{SF}}\right)$ and the evapotranspiration obtained through eddy covariance $\left(E_{\mathrm{EC}}\right)$ for sub-periods 1 and 2.

Barry (1978) indicated that when a final result is calculated from direct measurements, its precision is a function of the variability in the direct measurements. The plant transpiration is computed from direct measurements, including leaf transpiration and leaf area. Therefore, the standard error (SE) of $M_{P}$ can be expressed by $\mathrm{SE}$ of the direct measurements:

$\sigma_{M_{\mathrm{P}}}^{2}=\left(\sigma_{\mathrm{M}} \times A_{\text {plant }}\right)^{2}+\left(\sigma_{A_{\text {plant }}} \times M\right)^{2}$,

where $\sigma_{M_{\mathrm{P}}}, \sigma_{M}$, and $\sigma_{A_{\text {plant }}}$ are the standard errors for $M_{\mathrm{P}}$, $M$, and $A_{\text {plant }}$, respectively. The variability of $M$ and $A_{\text {plant }}$ is assumed to be normally distributed and independent since the $M$ and $A_{\text {plant }}$ are separately measured (Ham et al., 1990). Then we can rewrite Eq. (11) and express the variability of all parameters relative to their respective mean: 
Table 7. Evapotranspiration components $\left(\mathrm{mm} \mathrm{day}^{-1}\right)$ under mulched drip irrigation for the three sub-periods.

\begin{tabular}{lccrcccc}
\hline Sub-periods & $E_{\mathrm{P}}^{1}$ & $E_{\mathrm{EC}}^{2}$ & $\begin{array}{r}\text { Fraction of } \\
\text { transpiration } \\
\text { to ET (\%) }\end{array}$ & $E_{\text {soil }}^{3}$ & $\begin{array}{r}\text { Whole profile } \\
\mathrm{SWC}^{4}(\text { within } \\
20 \mathrm{~cm})\end{array}$ & $\begin{array}{c}\mathrm{IFZ}^{5} \mathrm{SWC}^{4} \\
\text { (within } \\
20 \mathrm{~cm})\end{array}$ & LAI $^{6}$ \\
\hline 23-25 Jul (SP1) & 5.004 & 3.941 & $87.1 \%$ & 0.508 & $24.2 \%$ & $20.0 \%$ & 3.080 \\
9-11 Aug (SP2) & 5.348 & 4.527 & $82.3 \%$ & 0.801 & $31.5 \%$ & $26.7 \%$ & 3.163 \\
16-18 Sep (SP3) & 4.396 & 3.014 & $100.0 \%$ & 0 & $17.9 \%$ & $15.6 \%$ & 2.402 \\
\hline
\end{tabular}

${ }^{1} E_{\mathrm{P}}$ : ET calculated by the FAO Penman-Monteith equation; ${ }^{2} E_{\mathrm{EC}}:$ ET measured by eddy covariance; ${ }^{3} E_{\text {soil }}:$ soil evaporation calculated by the multiplication of $E_{\mathrm{EC}}$ by the fraction of transpiration to ET; ${ }^{4} \mathrm{SWC}$ : soil water content; ${ }^{5} \mathrm{IFZ}$ : inter-film zone; ${ }^{6} \mathrm{LAI}$ : leaf area index.

$\frac{\sigma_{M_{\mathrm{P}}}}{M_{\mathrm{P}}}=\left[\left(\frac{\sigma_{\mathrm{M}}}{M}\right)^{2}+\left(\frac{\sigma_{A_{\text {plant }}}}{A_{\text {plant }}}\right)^{2}\right]^{\frac{1}{2}}$.

This analysis shows that both the variability of $M$ and $A_{\text {plant }}$ affect the variability of plant transpiration estimate. In this study, $\frac{\sigma_{A_{\text {plant }}}}{A_{\text {plant }}}$ has been determined based on the data, whose value is 0.018. As shown in Sect. 3.2.1, in Approach 1, $\frac{\sigma_{\mathrm{M}}}{M}$ is the variability in leaf transpiration at the plant level, whose value is 0.310 . Therefore, $\frac{\sigma_{M_{\mathrm{P}}}}{M_{\mathrm{P}}}$ is equal to 0.311 . It is worth noting that if we take the transpiration difference of sunlit leaf and shaded leaf into account, the $\frac{\sigma_{M}}{M}$ should be larger and the $\frac{\sigma_{M_{\mathrm{P}}}}{M_{\mathrm{P}}}$ will increase, accordingly.

Similarly, we can assess the flux uncertainties of Approach 2. When we assume that the $\frac{\sigma_{\mathrm{M}}}{M}$ and $\frac{\sigma_{A_{\text {plant }}}}{A_{\text {plant }}}$ are constant in different canopy layers, the variability of plant transpiration can be obtained by the following equation:

$\frac{\sigma_{M_{\mathrm{P}}}}{M_{\mathrm{P}}}=\left\{\left[\frac{M_{\mathrm{P} 1}^{2}+M_{\mathrm{P} 2}^{2}+M_{\mathrm{P} 3}^{2}}{M_{\mathrm{P}}^{2}}\right] \cdot\left[\left(\frac{\sigma_{\mathrm{M}}}{M}\right)^{2}+\left(\frac{\sigma_{A_{\mathrm{plant}}}}{A_{\text {plant }}}\right)^{2}\right]\right\}^{\frac{1}{2}}$,

where $M_{\mathrm{P} i}$ is the plant transpiration of the canopy layer $i$. In this study, $\frac{\sigma_{A_{\text {plant }}}}{A_{\text {plant }}}$ is 0.018 , and $\frac{\sigma_{\mathrm{M}}}{M}$ is the variability in leaf transpiration at the layer level, whose value is $0.160 . \frac{\sigma_{M_{\mathrm{P}}}}{M_{\mathrm{P}}}$ is equal to 0.161 when $\left[\frac{M_{\mathrm{P} 1}^{2}+M_{\mathrm{P} 2}^{2}+M_{\mathrm{P} 3}^{2}}{M_{\mathrm{P}}^{2}}\right]$ is 1 . However, since $\left[\frac{M_{\mathrm{P} 1}^{2}+M_{\mathrm{P} 2}^{2}+M_{\mathrm{P} 3}^{2}}{M_{\mathrm{P}}^{2}}\right]$ is always less than $1, \frac{\sigma_{M_{\mathrm{P}}}}{M_{\mathrm{P}}}$ would be less than 0.161 in Approach 2. The results suggest that the variability of plant transpiration will sharply decrease when the canopy structure has been considered. Compared with Approach 1, Approach 2 provides us more reliable upscaled transpiration at the plant scale.

\subsubsection{Field scale}

In Approach 3, the field transpiration is calculated by the following equation:

$E_{\mathrm{SF}}=F_{\mathrm{P}} \times n$, where $F_{\mathrm{P}}$ is sap flow value per plant, and $n$ is the plant density. Similarly, we can also rewrite Eq. (14) to express the variability of all parameters relative to their respective mean:

$\frac{\sigma_{E_{\mathrm{SF}}}}{E_{\mathrm{SF}}}=\left[\left(\frac{\sigma_{F_{\mathrm{P}}}}{F_{\mathrm{P}}}\right)^{2}+\left(\frac{\sigma_{n}}{n}\right)^{2}\right]^{\frac{1}{2}}$,

where $\sigma_{E_{\mathrm{SF}}}, \sigma_{F_{\mathrm{P}}}$ and $\sigma_{n}$ are the standard errors for $E_{\mathrm{SF}}, F_{\mathrm{P}}$ and $n$, respectively. Based on the measurements, $\frac{\sigma_{F_{\mathrm{P}}}}{F_{\mathrm{P}}}$ is determined as 0.151 in Sect. 3.3.1 and $\frac{\sigma_{n}}{n}$ is 0.040. Therefore, $\frac{\sigma_{E_{\mathrm{SF}}}}{E_{\mathrm{SF}}}$ in Approach 3 has the value of 0.156 in this study.

Similarly, the $\frac{\sigma_{E_{\mathrm{SF}}}}{E_{\mathrm{SF}}}$ can be calculated using Eq. (16) in Approach 4, and Eq. (17) in Approach 5 and 6, respectively. $F_{\text {Pstem }}$ is sap flow value per unit stem diameter, $S_{\text {rep }}$ is the representative stem diameter for typical plant, $F_{\mathrm{PA}}$ is sap flow value per unit leaf area, and $A_{\text {rep }}$ is the representative leaf area for typical plant. $\frac{\sigma_{F_{\mathrm{Pstem}}}}{F_{\mathrm{Pstem}}}$ and $\frac{\sigma_{\mathrm{F}}}{F_{\mathrm{PA}}}$ are determined based on the measurements, whose values are 0.105 and 0.035 , respectively. $\frac{\sigma_{n}}{n}$ is 0.040 as mentioned before. Since we have measured 2000 plants to obtain the representative stem diameter, it is reasonable to assume $\frac{\sigma_{\text {rep }}}{S_{\text {rep }}}$ is small. In this study, $\frac{\sigma_{S_{\text {rep }}}}{S_{\text {rep }}}$ is assigned to $0.05 . \frac{\sigma_{\mathrm{A}}}{A_{\text {rep }}}$ is influenced by both variability of the relationship between leaf area and stem diameter, and the stem diameter variability $\frac{\sigma_{\text {rep }}}{S_{\text {rep }}}$. In Approach $5, \frac{\sigma_{\mathrm{A}}}{A_{\text {rep }}}$ is assumed to be 0.1 . Given that we have adopted dynamic relationships for different cotton growth stages in Approach 6, $\frac{\sigma_{\mathrm{A}}}{A_{\text {rep }}}$ is assigned to 0.05 .

$\frac{\sigma_{E_{\mathrm{SF}}}}{E_{\mathrm{SF}}}=\left[\left(\frac{\sigma_{F_{\mathrm{Pstem}}}}{F_{\mathrm{Pstem}}}\right)^{2}+\left(\frac{\sigma_{S_{\text {rep }}}}{S_{\text {rep }}}\right)^{2}+\left(\frac{\sigma_{n}}{n}\right)^{2}\right]^{\frac{1}{2}}$,
$\frac{\sigma_{E_{\mathrm{SF}}}}{E_{\mathrm{SF}}}=\left[\left(\frac{\sigma_{\mathrm{F}}}{F_{\mathrm{PA}}}\right)^{2}+\left(\frac{\sigma_{\mathrm{A}}}{A_{\text {rep }}}\right)^{2}+\left(\frac{\sigma_{n}}{n}\right)^{2}\right]^{\frac{1}{2}}$

The final results of error analysis are shown in Table 5. $\frac{\sigma_{E_{\mathrm{SF}}}}{E_{\mathrm{SF}}}$ is 0.123 in Approach 4, 0.113 in Approach 5, and 0.073 in Approach 6, respectively. The results suggest that although Approach 6 introduces more parameters into the field transpiration estimate, the flux uncertainty has been reduced in 
this approach. That is because the variability of sap flow rates are reduced when the rates are expressed on unit leaf area. Meanwhile, the variability of leaf area estimate has been reduced by the application of a dynamic relationship between leaf area and stem diameter. That is to say, from the statistical perspective, Approach 6 provides us the most reliable upscaled transpiration at the field scale in this study.

\subsubsection{Soil evaporation}

Soil evaporation is calculated in Sect. 3.3.5 by the following equation:

$E_{\text {soil }}=E_{\mathrm{EC}}-F_{\mathrm{PA}} \times A_{\text {rep }} \times n$.

The soil evaporation is computed from direct measurements including eddy covariance, sap flow, leaf area and plant density. Therefore, the standard error (SE) of $E_{\text {soil }}$ can be expressed by SE of the direct measurements:

$$
\begin{aligned}
\sigma_{\text {soil }}^{2} & =\sigma_{\mathrm{EC}}^{2}+\left(\sigma_{\mathrm{F}} \times A_{\text {rep }} \times n\right)^{2}+\left(\sigma_{\mathrm{A}} \times F_{\mathrm{PA}} \times n\right)^{2} \\
& +\left(F_{\mathrm{PA}} \times A_{\text {rep }} \times \sigma_{n}\right)^{2} .
\end{aligned}
$$

We can also rewrite Eq. (19) as follows:

$$
\begin{aligned}
& \frac{\sigma_{\text {soil }}}{E_{\text {soil }}}=\left\{\left(\frac{E_{\text {soil }}}{E_{\mathrm{EC}}}\right)^{-2}\left(\frac{\sigma_{\mathrm{EC}}}{E_{\mathrm{EC}}}\right)^{2}+\left[\left(\frac{E_{\text {soil }}}{E_{\mathrm{EC}}}\right)^{-1}-1\right]^{2}\right. \\
& {\left.\left[\left(\frac{\sigma_{\mathrm{F}}}{F_{\mathrm{PA}}}\right)^{2}+\left(\frac{\sigma_{\mathrm{A}}}{A_{\text {rep }}}\right)^{2}+\left(\frac{\sigma_{n}}{n}\right)^{2}\right]\right\}^{\frac{1}{2}} }
\end{aligned}
$$

This analysis shows that the variability of $E_{\mathrm{EC}}$ plays an important role when $\frac{E_{\text {soil }}}{E_{\mathrm{EC}}}$ is large. When $\frac{E_{\text {soil }}}{E_{\mathrm{EC}}}$ becomes small, the variabilities of $F_{\mathrm{PA}}, A_{\text {rep }}$ and $n$ are more significant in the estimate of soil evaporation.

As mentioned above, $\frac{\sigma_{\mathrm{F}}}{F_{\mathrm{PA}}}$ and $\frac{\sigma_{n}}{n}$ are 0.035 and 0.040 , respectively (Approach 6). Since ET measured by eddy covariance is relatively stable, we can suppose that $\frac{\sigma_{\mathrm{EC}}}{E_{\mathrm{EC}}}$ is quite small with the value of $0.001 . \frac{\sigma_{\mathrm{A}}}{A_{\text {rep }}}$ is assigned to 0.1 and 0.05 for comparison.

The behavior of Eq. (20) is demonstrated in Fig. 15 when using these typical variance levels mentioned above. When $\frac{E_{\text {soil }}}{E_{\mathrm{EC}}}$ becomes smaller, the expected $\frac{\sigma_{\text {soil }}}{E_{\mathrm{soil}}}$ increases sharply, and the measurements of sap flow, leaf area and plant density are more significant. In this study, the $\frac{E_{\mathrm{soil}}}{E_{\mathrm{EC}}}$ is approximately $15 \%$, and then the $\frac{\sigma_{\text {soil }}}{E_{\text {soil }}}$ is about $0.64\left(\frac{\sigma_{\mathrm{A}}}{A_{\text {rep }}}=0.1\right)$ and 0.41 $\left(\frac{\sigma_{\mathrm{A}}}{A_{\text {rep }}}=0.05\right)$. The results indicate that the soil evaporation is difficult to evaluate under mulched drip irrigation conditions when $E_{\text {soil }}$ is the small component of ET. The comparison of two curves in Fig. 15 shows that the variability of $E_{\text {soil }}$ has not been markedly reduced when only $\frac{\sigma_{\mathrm{A}}}{A_{\text {rep }}}$ decreases. That is to say, the variability of $E_{\text {soil }}$ will not be reduced until the measurements of sap flow, LAI and plant density are improved simultaneously.

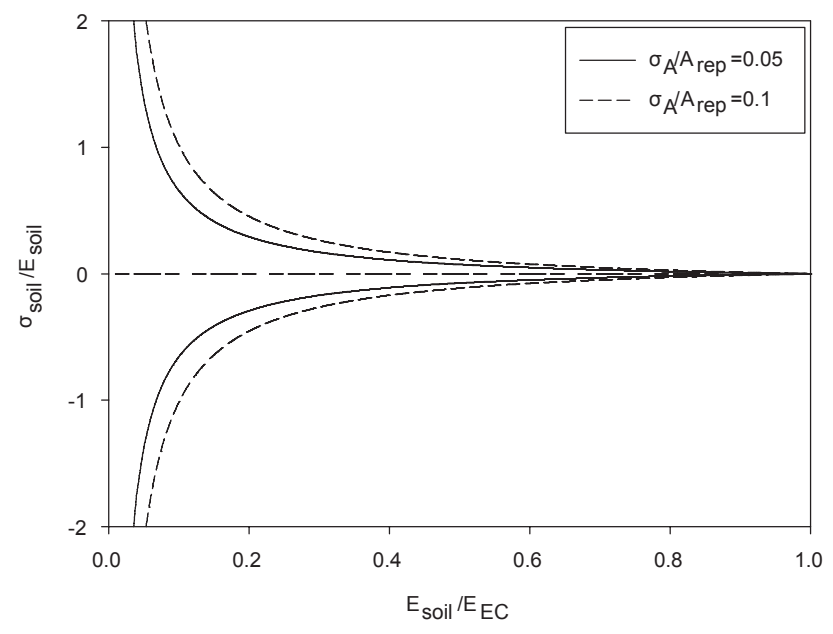

Fig. 15. Expected variability of soil evaporation estimate $\left(\frac{\sigma_{\text {soil }}}{E_{\text {soil }}}\right)$ in response to the fraction of evaporation over ET (Eq. 20). The curves show the variability for the different $\frac{\sigma_{\mathrm{A}}}{A_{\text {rep }}}$ levels. $\frac{\sigma_{\mathrm{EC}}}{E_{\mathrm{EC}}}, \frac{\sigma_{\mathrm{F}}}{F_{\mathrm{PA}}}$ and $\frac{\sigma_{n}}{n}$ are held constant at $0.001,0.035$ and 0.040 , respectively.

\section{Discussion}

Three different measurement methods, namely the photosynthesis system, sap flow, and eddy covariance, were used in this study to estimate evapotranspiration in a cotton field under mulched drip irrigation. Although these three methods differ significantly in the physical theories on which the measurements are based and the particular spatial and temporal scales to which they pertain, the results derived from each of the measurements after scale transformation show satisfactory consistency when employed during the cotton growth season. The reasonably good agreement between the results obtained using LCpro+, sap flow, and eddy covariance provides some confidence in their reliability for the estimation of the evapotranspiration in an agricultural ecosystem using these three methods and the described upscaling approaches.

In farmland, the partitioning of evapotranspiration components is essential for guiding the irrigation schedule to achieve the dual goals of water saving and high yield (Wang et al., 2001). Since this type of investigation needs the data measured at different spatial scales, scale transformation should be implemented. Different species have different transpiration characters. In addition, the transpiration rates of leaves vary substantially depending on the leaf's position, orientation, age, and size (Sassenrath-Cole, 1995; Thanisawanyangkura et al., 1997), and the transpiration of plants also varies markedly with the heterogeneous soil water availability, the diverse plant age and LAI (Dugas, 1990). Therefore, it is more simple to conduct scale transformation in farmland than in forest due to the single crop species planted, the relatively homogeneous vegetation distribution pattern, and the low spatial variability in the water availability (Loranty et al., 2008), which make it straightforward 
and feasible to extrapolate point observations to representative area values, and lead to highly credible and reasonable scaled results (Allen et al., 2011a). However, it is also a challenge to conduct scale transformation in farmland due to rapid crop growth, rapid changes in leaf area and stem diameter, and large diversity in growth conditions among plants, all of which affect the results and introduce errors (Chabot et al., 2005).

In this study, taking into account the rapid growth of the plants, we establish links between leaf areas and stem diameters during every sub-period for the scale transformation. This approach overcomes the limitation caused by rapid growth and achieves a good result for the derivation of the field leaf area. Plant transpiration derived from the photosynthesis system has seldom been reported before. Because the number of samples measured by instruments is limited compared to the large number of leaves and because there is considerable variability among the leaves, it is quite difficult to extrapolate photosynthesis system measurements to the plant scale (Dugas et al., 1994; Kigalu, 2007). In this study, the different transpiration rates of sunlit and shaded leaves, as well as canopy structure, were taken into account. This upscaling approach was proven to provide a reasonable estimation of transpiration at the plant scale.

However, discrepancy still exists among ET results obtained using the photosynthesis system, sap flow, and eddy covariance. The upscaling approaches used to transform ET from the leaf- to the plant scale or from the plant- to the field scale may lead to errors and result in discrepancies. First, the photosynthesis system and sap flow methods can measure only a subset of leaves or plants in a field. These limited samples sometimes do not completely capture the variance and the mean response of the overall situation in which the target scaling level method operates. In addition, the canopy parameters and the ratio of the transpiration rate of a shaded leaf to that of a sunlit leaf, which were derived from the literature, may vary from the actual values (Petersen et al., 1992; Thanisawanyangkura et al., 1997). The simultaneous observation of canopy structure is expected to improve the results. Another possible source of divergence between the LCpro+, sap flow, and eddy covariance results could be the unmatched observation area. Although LCpro+ and sap flow measurements and the leaf area estimates were conducted within the flux source footprint of eddy covariance, the changing wind direction and footprint might change the measuring area of eddy covariance and frustrate attempts to match the scaled transpiration to the eddy covariance measurements (Williams et al., 2004).

As with any other measurement techniques, photosynthesis system, sap flow and eddy covariance methods have their own inherent limitations which should be mentioned (Good et al., 2012). It is reported in previous studies that sap flow overestimates transpiration by $7-35 \%$ (Chabot et al., 2005; Ham et al., 1990) due to the stem heat storage, heat dissipation to the ambient environment and accuracy of stem temperature measurements. For eddy covariance, it is a known phenomenon that the observation likely underestimates ET at field scale (Foken, 2008; Wilson et al., 2002). Discrepancy might also come from these inherent factors mentioned above.

Due to the severe lack of water resources in arid and semiarid regions, mulched drip irrigation has been widely applied as a highly efficient water-saving irrigation method (Wang et al., 2011). As shown in the evapotranspiration partition results in this study, a portion of soil evaporation is significantly reduced through mulched drip irrigation, and most of the water is consumed by plant transpiration during the analysis periods. Because transpiration is accompanied by photosynthesis and plant productivity, higher transpiration indicates a better crop yield (Katul et al., 2012), and mulched drip irrigation tends to improve water use efficiency. Compared to the fraction of cotton transpiration to evapotranspiration of $65 \%$ (Tang et al., 2010) and 56\% (Ham et al., 1990) observed under traditional flood irrigation conditions during the same cotton growth stages (flower and bolling stages), the fraction of $87.1 \%$ before irrigation and $82.3 \%$ after irrigation that were obtained in this study are much higher, which confirms that mulched drip irrigation is a more efficient method for achieving water savings. The quantitative estimation of evaporation and transpiration in this study may provide supports for the application of mulched drip irrigation in the future.

\section{Conclusions}

A comparison of the methods used to determine evapotranspiration and its components in a cotton field under mulched drip irrigation conditions was conducted in this study. The methods used were based on a photosynthesis system, sap flow, and eddy covariance, which provided information at the leaf-, plant-, and field scale, respectively. The variability in the transpiration at the leaf scale and at the plant scale was discussed. Upscaling approaches were explored to obtain comparable ET estimates from the multi-scale measurements. The results show that ET estimates derived from the three methods agree well after scale transformation, which indicates that, taking into account the variability between individuals, the selection of representative samples, and the adoption of a suitable scale transformation approach, any of these three methods can provide good estimates of field evapotranspiration in farmland.

The comparison of the methods and the discussion of the variability associated with the three ET measurement methods will help researchers assess the quality, validity, and representativeness of ET information derived using these techniques. The upscaling approaches can help other researchers estimate field evapotranspiration from point measurements, such as those obtained based on photosynthesis system and sap flow, and will provide data and precedent for 
further study on the water cycle and ecological processes in farmland.

Based on the transpiration estimates obtained from the upscaling of sap flow measurements and ET obtained through eddy covariance, the evapotranspiration components were analyzed. The evapotranspiration rates were determined to 3.94 and $4.53 \mathrm{~mm} \mathrm{day}^{-1}$ during the cotton flower (July) and bolling (August) stages, respectively. The results show that a fraction of transpiration over ET is significantly increased under mulched drip irrigation during cotton flower and bolling stages. The fraction of transpiration to evapotranspiration reached $87.1 \%$ before drip irrigation and $82.3 \%$ after irrigation during the analysis periods. The results might support the popularization of mulched drip irrigation in other arid and semi-arid regions in the future to address the challenge of water scarcity.

Acknowledgements. This study was supported by the National Science Foundation of China (NSFC 51190092, 51109110, and 51222901), SRF for ROCS, SEM, and the Foundation of the State Key Laboratory of Hydroscience and Engineering of Tsinghua University (2012-KY-03). Their support is greatly appreciated. We also thank the staff at Tsinghua University-Korla Oasis Eco-hydrology Experimental Research Station for their excellent field and lab assistance. We thank Murugesu Sivapalan from the University of Illinois at Urbana-Champaign and Huimin Lei from Tsinghua University for their helpful advice. Also, we would like to give our sincere thanks to the reviewers (Xianwen Li, S. P. Good, and B. Mitra) for all their comments which improve the quality of manuscript substantially.

Edited by: L. Wang

\section{References}

ADC Bioscientific Ltd.: LCi Portable Photosynthesis System: Instruction Manual, ADC BioScientific Ltd., Hoddesdon, UK, 2004.

Alfieri, J. G., Kustas, W. P., Prueger, J. H., Hipps, L. E., Evett, S. R., Basara, J. B., Neale, C. M. U., French, A. N., Colaizzi, P., Agam, N., Cosh, M. H., Chavez, J. L., and Howell, T. A.: On the discrepancy between eddy covariance and lysimetry-based surface flux measurements under strongly advective conditions, Adv. Water Resour., 50, 62-78, 2012.

Allen, R. G., Pereira, L. S., Raes, D., and Smith, M.: FAO Irrigation and drainage paper No. 56, Food and Agriculture Organization of the United Nations, Roma, Italy, 1998.

Allen, R. G., Pereira, L. S., Howell, T. A., and Jensen, M. E.: Evapotranspiration information reporting: I. Factors governing measurement accuracy, Agr. Water Manage., 98, 899-920, 2011 a.

Allen, R. G., Pereira, L. S., Howell, T. A., and Jensen, M. E.: Evapotranspiration information reporting: II. Recommended documentation, Agr. Water Manage., 98, 921-929, 2011 b.
Ashraf, M.: Salt tolerance of cotton: Some new advances, Crit. Rev. Plant Sci., 21, 1-30, 2002.

Baker, J. M. and Vanbavel, C.: Measurement of mass-flow of water in the stems of herbaceous plants, Plant Cell Environ., 10, 777782, 1987.

Baldocchi, D., Falge, E., Gu, L. H., Olson, R., Hollinger, D., Running, S., Anthoni, P., Bernhofer, C., Davis, K., Evans, R., Fuentes, J., Goldstein, A., Katul, G., Law, B., Lee, X. H., Malhi, Y., Meyers, T., Munger, W., Oechel, W., Paw U, K. T., Pilegaard, K., Schmid, H. P., Valentini, R., Verma, S., Vesala, T., Wilson, K., and Wofsy, S.: FLUXNET: a new tool to study the temporal and spatial variability of ecosystem-scale carbon dioxide, water vapor, and energy flux densities, B. Am. Meteorol. Soc., 82, 2415-2434, 2001.

Barry, B. A.: Errors in practical measurement in science, engineering and technology, Wiley, New York, 1978.

Bonachela, S., Orgaz, F., Villalobos, F. J., and Fereres, E.: Soil evaporation from drip-irrigated olive orchards, Irrig. Sci., 20, 65-71, 2001.

Chabot, R., Bouarfa, S., Zimmer, D., Chaumont, C., and Moreau, S.: Evaluation of the sap flow determined with a heat balance method to measure the transpiration of a sugarcane canopy, Agr. Water Manage., 75, 10-24, 2005.

Chavez J. L., Howell, T. A., and Copeland, K. S.: Evaluating eddy covariance cotton ET measurements in an advective environment with large weighing lysimeters, Irrig. Sci., 28, 35-=50, 2009.

Ding, R., Kang, S., Li, F., Zhang, Y., Tong, L., and Sun, Q.: Evaluating eddy covariance method by large-scale weighing lysimeter in a maize field of northwest China, Agr. Water Manage., 98, 87-95, 2010.

Dugas, W. A.: Comparative measurement of stem flow and transpiration in cotton, Theor. Appl. Climatol., 42, 215-221, 1990.

Dugas, W. A., Heuer, M. L., Hunsaker, D., Kimball, B. A., Lewin, K. F., Nagy, J., and Johnson, M.: Sap flow measurements of transpiration from cotton grown under ambient and enriched $\mathrm{CO}_{2}$ concentrations, Agr. Forest. Meteorol., 70, 231-245, 1994.

Evett, S. R., Kustas, W. P., Gowda, P. H., Anderson, M. C., Prueger, J. H., and Howell, T. A.: Overview of the bushland evapotranspiration and agricultural remote sensing experiment 2008 (BEAREX08): a field experiment evaluating methods for quantifying ET at multiple scales, Adv. Water Resour, 50, 4-19, doi:10.1016/j.advwatres.2012.03.010, 2012.

Falge, E., Baldocchi, D., Olson, R., Anthoni, P., Aubinet, M., Bernhofer, C., Burba, G., Ceulemans, R., Clement, R., Dolman, H., Granier, A., Gross, P., Grunwald, T., Hollinger, D., Jensen, N. O., Katul, G., Keronen, P., Kowalski, A., Lai, C. T., Law, B. E., Meyers, T., Moncrieff, H., Moors, E., Munger, J. W., Pilegaard, K., Rannik, U., Rebmann, C., Suyker, A., Tenhunen, J., Tu, K., Verma, S., Vesala, T., Wilson, K., and Wofsy, S.: Gap filling strategies for defensible annual sums of net ecosystem exchange, Agr. Forest. Meteorol., 107, 43-69, 2001.

Foken, T.: The energy balance closure problem: An overview, Ecol. Appl., 18, 1351-1367, 2008.

Franssen, H. J., Stöckli, R., Lehner, I., Rotenberg, E., and Seneviratne, S. I.: Energy balance closure of eddy-covariance data: A multisite analysis for European FLUXNET stations, Agr. Forest. Meteorol., 150, 1553-1567, 2010. 
Good, S. P., Soderberg, K., Wang, L., and Caylor, K. K.: Uncertainties in the assessment of the isotopic composition of surface fluxes: A direct comparison of techniques using laser-based water vapor isotope analyzers, J. Geophys. Res., 117, D15301, doi:10.1029/2011JD017168, 2012.

Granier, A., Biron, P., and Lemoine, D.: Water balance, transpiration and canopy conductance in two beech stands, Agr. Forest. Meteorol., 100, 291-308, 2000.

Ham, J. M., Heilman, J. L., and Lascano, R. J.: Determination of soil-water evaporation and transpiration from energy-balance and stem-flow measurements, Agr. Forest. Meteorol., 52, 287301,1990

Hatton, T. J. and Wu, H. I.: Scaling theory to extrapolate individual tree water-use to stand water-use, Hydrol. Process., 9, 527-540, 1995.

Heilman, J. L. and Ham, J. M.: Measurement of mass-flow rate of sap in ligustrum-japonicum, Hortscience, 25, 465-467, 1990.

Hou, X., Wang, F., Han, J., Kang, S., and Feng, S.: Duration of plastic mulch for potato growth under drip irrigation in an arid region of northwest China, Agr. Forest. Meteorol., 150, 115-121, 2010.

Howell, T. A., Evett, S. R., Tolk, J. A., and Schneider, A. D.: Evapotranspiration of full-, deficit-irrigated, and dryland cotton on the northern Texas high plains, J. Irrig. Drain. E.-ASCE., 130, $277-$ 285,2004

$\mathrm{Hu}, \mathrm{H}$., Tian, F., and Hu, H.: Soil particle size distribution and its relationship with soil water and salt under mulched drip irrigation in Xinjiang Province of China, Sci. China Tech. Sci., 54, 1-7, 2011.

Katul, G. G., Oren, R., Manzoni, S., Higgins, C., and Parlange, M. B.: Evapotranspiration: A process driving mass transport and energy exchange in the soil-plant-atmosphere-climate system, Rev. Geophys., 50, RG3002, doi:10.1029/2011RG000366, 2012.

Kigalu, J. M.: Effects of planting density on the productivity and water use of tea (Camellia sinensis L.) clones I. Measurement of water use in young tea using sap flow meters with a stem heat balance method, Agr. Water Manage., 90, 224-232, 2007.

Ko, J., Piccinni, G., Marek, T., and Howell, T.: Determination of growth-stage-specific crop coefficients $\left(K_{\mathrm{C}}\right)$ of cotton and wheat, Agr. Water Manage., 96, 1691-1697, 2009.

Lei, H. and Yang, D.: Interannual and seasonal variability in evapotranspiration and energy partitioning over an irrigated cropland in the North China Plain, Agr. Forest. Meteorol., 150, 581-589, 2010.

Leuning, R., Van Gorsel, E., Massman, W. J., and Isaac, P. R.: Reflections on the surface energy imbalance problem, Agric. Forest. Meteorol., 156, 65-74, 2012.

Li, S., Kang, S., Li, F., and Zhang, L.: Evapotranspiration and crop coefficient of spring maize with plastic mulch using eddy covariance in northwest China, Agr. Water Manage., 95, 1214-1222, 2008.

Loranty, M. M., Mackay, D. S., Ewers, B. E., Adelman, J. D., and Kruger, E. L.: Environmental drivers of spatial variation in whole-tree transpiration in an aspen-dominated uplandto-wetland forest gradient, Water Resour. Res., 44, W02441, doi:10.1029/2007WR006272, 2008.
MacKay, D. S., Ahl, D. E., Ewers, B. E., Gower, S. T., Burrows, S. N., Samanta, S., and Davis, K. J.: Effects of aggregated classifications of forest composition on estimates of evapotranspiration in a northern Wisconsin forest, Global Change Biol., 8, 1253 1265, 2002.

Mahouachi, J., Socorro, A. R., and Talon, M.: Responses of papaya seedlings (Carica papaya L.) to water stress and re-hydration: Growth, photosynthesis and mineral nutrient imbalance, Plant Soil, 281, 137-146, 2006.

Mengistu, T., Sterck, F. J., Fetene, M., Tadesse, W., and Bongers, F.: Leaf gas exchange in the frankincense tree (Boswellia papyrifera) of African dry woodlands, Tree Physiol., 31, 740-750, 2011.

Petersen, K. L., Fuchs, M., Moreshet, S., Cohen, Y., and Sinoquet, H.: Computing transpiration of sunlit and shaded cotton foliage under various water stresss, Agron. J., 84, 91-97, 1992.

Sakuratani, T.: A heat balance method for measuring water flux in the stem of intact plants, J. Agr. Meteorol., 37, 9-17, 1981.

Sakuratani, T.: Improvement of the probe for measuring water flow rate in intact plants with the stem heat balance method, J. Agrometeorol., 40, 273-277, 1984.

Sarlikioti, V., de Visser, P., and Marcelis, L.: Exploring the spatial distribution of light interception and photosynthesis of canopies by means of a functional-structural plant model, Ann. Bot., 107, 875-883, 2011.

Sassenrath-Cole, G. F.: Dependence of canopy light distribution on leaf and canopy structure for two cotton (Gossypium) species, Agr. Forest. Meteorol., 77, 55-72, 1995.

Silberstein, R., Held, A., Hatton, T., Viney, N., and Sivapalan, M.: Energy balance of a natural jarrah (Eucalyptus marginata) forest in Western Australia: measurements during the spring and summer, Agr. Forest. Meteorol., 109, 79-104, 2001.

Stoy, P. C., Mauder, M., Foken, T., Marcolla, B., Boegh, E., Ibrom, A., Arain, M. A., Arneth, A., Aurela, M., Bernhofer, C., Cescatti, A., Dellwik, E., Duce, P., Gianelle, D., van Gorsel, E., Kiely, G., Knohl, A., Margolis, H., McCaughey, H., Merbold, L., Montagnani, L., Papale, D., Reichstein, M., Saunders, M., Serrano-Ortiz, P., Sottocornola, M., Spano, D., Vaccari, F., and Varlagin, A.: A data-driven analysis of energy balance closure across FLUXNET research sites: The role of landscape scale heterogeneity, Agr. Forest. Meteorol., 171-172, 137-152, 2013.

Tang, L., Li, Y., and Zhang, J.: Partial rootzone irrigation increases water use efficiency, maintains yield and enhances economic profit of cotton in arid area, Agr. Water Manage., 97, 1527-1533, 2010.

Tao, Y.: Contrusting physiological properties of shaded and sunlit leaves, and applying a photosynthesis model for cotton, Nanjing University of Information Science \& Technology, Nanjing, 2007.

Thanisawanyangkura, S., Sinoquet, H., Rivet, P., Cretenet, M., and Jallas, E.: Leaf orientation and sunlit leaf area distribution in cotton, Agr. Forest. Meteorol., 86, 1-15, 1997.

Tolk, J. A., Howell, T. A., and Evett, S. R.: Nighttime evapotranspiration from alfalfa and cotton in a semiarid climate, Agron. J., 98, 730-736, 2006.

van Dijk, A., Moene, A. F., and de Bruin, H. A. R.: The principles of surface flux physics: theory, practice and description of the ECPACK library, Internal Report 2004/1, Meteorology and Air Quality Group, Wageningen University, Wageningen, the Netherlands, 99 pp., 2004. 
Wang, H., Zhang, L., Dawes, W. R., and Liu, C.: Improving water use efficiency of irrigated crops in the North China Plain measurements and modeling, Agr. Water Manage., 48, 151-167, 2001.

Wang, L., Caylor, K. K., Villegas, J. C., Barron-Gafford, G. A., Breshears, D. D., and Huxman, T. E.: Partitioning evapotranspiration across gradients of woody plant cover: Assessment of a stable isotope technique, Geophys. Res. Lett., 37, L09401, doi:10.1029/2010GL043228, 2010.

Wang, L., Niu, S., Good, S. P., Soderberg, K., McCabe, M. F., Sherry, R. A., Luo, Y., Zhou, X., Xia, J., and Caylor, K. K.: The effect of warming on grassland evapotranspiration partitioning using laser-based isotope monitoring techniques, Geochim. Cosmochim. Acta, 111, 28-38, 2013.

Wang, R., Kang, Y., Wan, S., Hu, W., Liu, S., and Liu, S.: Salt distribution and the growth of cotton under different drip irrigation regimes in a saline area, Agr. Water Manage., 100, 58-69, 2011.

Webb, E. K., Pearman, G. I., and Leuning, R.: Correction of flux measurements for density effects due to heat and water vapour transfer, Q. J. Roy. Meteorol. Soc., 106, 85-100, 1980.

Williams, D. G., Cable, W., Hultine, K., Hoedjes, J. C. B., Yepez, E. A., Simonneaux, V., Er-Raki, S., Boulet, G., de Bruin, H. A. R., Chehbouni, A., Hartogensis, O. K., and Timouk, F.: Evapotranspiration components determined by stable isotope, sap flow and eddy covariance techniques, Agr. Forest. Meteorol., 125, 241258, 2004.
Wilson, K. B., Hanson, P. J., Mulholland, P. J., Baldocchi, D. D., and Wullschleger, S. D.: A comparison of methods for determining forest evapotranspiration and its components: sap-flow, soil water budget, eddy covariance and catchment water balance, Agr. Forest. Meteorol., 106, 153-168, 2001.

Wilson, K., Goldstein, A., Falge, E., Aubinet, M., Baldocchi, D., Berbigier, P., Bernhofer, C., Ceulemans, R., Dolmanh, H., Field, C., Grelle, A., Ibrom, A., Lawl, B. E., Kowalski, A., Meyers, T., Moncrieffm, J., Monsonn, R., Oechel, W., Tenhunen, J., Valentini, R., and Verma, S.: Energy balance closure at FLUXNET sites, Agr. Forest. Meteorol., 113, 223-243, 2002.

Zhang, J., Wang, Y., Mao, W., Dong, Q., and Zhao, Y.: Dynamic Simulation of leaf area in cotton canopy, Trans. Chin. Soc. Agric. Mach., 38, 117-120, 2007.

Zhang, Z., Hu, H. C., Tian, F., Hu, H. P., Yao, X., and Zhong, R.: Soil salt distribution under mulched drip irrigation in an arid area of northwestern China, J. Arid. Environ., 104, 23-33, doi:10.1016/j.jaridenv.2014.01.012, 2014.

Zhou, S., Wang, J., Liu, J., Yang, J., Xu, Y., and Li, J.: Evapotranspiration of a drip-irrigated, film-mulched cotton field in northern Xinjiang, China, Hydrol. Process., 26, 1169-1178, doi:10.1002/hyp.8208, 2011. 